This item was submitted to Loughborough's Research Repository by the author.

Items in Figshare are protected by copyright, with all rights reserved, unless otherwise indicated.

\title{
Strength parameter selection framework for evaluating the design life of clay cut slopes
}

PLEASE CITE THE PUBLISHED VERSION

https://doi.org/10.1680/jgeen.21.00125

PUBLISHER

Thomas Telford Ltd.

VERSION

VoR (Version of Record)

\section{PUBLISHER STATEMENT}

This is an Open Access Article. It is published by Thomas Telford under the Creative Commons Attribution 4.0 Unported Licence (CC BY). Full details of this licence are available at: http://creativecommons.org/licenses/by/4.0/

\section{LICENCE}

CC BY 4.0

\section{REPOSITORY RECORD}

Postill, Harry, Peter R Helm, Neil Dixon, Ashraf El-Hamalawi, S Glendinning, and WA Take. 2021. "Strength Parameter Selection Framework for Evaluating the Design Life of Clay Cut Slopes". Loughborough University. https://hdl.handle.net/2134/16752229.v1. 


\title{
Strength parameter selection framework for evalu- ating the design life of clay cut slopes
}

\author{
Postill, H. ${ }^{\text {a }}$; Helm, P.R. ${ }^{\text {; }}$ Dixon, N. ${ }^{\text {a }}$ El-Hamalawi, A. ${ }^{\text {a }}$; Glendinning, S. ${ }^{\text {b }}$ \& Take, W.A. ${ }^{\text {c }}$ \\ ${ }^{a}$ Loughborough University, UK; ${ }^{\mathrm{b}}$ Newcastle University, UK; ' Queen's University, Canada \\ Corresponding author: peter.helm@ncl.ac.uk
}

\begin{abstract}
Design of engineered earthworks is predominately conducted through limit equilibrium analysis requiring strain independent strength criteria. Previous studies for deep-seated first-time failures within over-consolidated clay cut slopes have proposed the use of fully softened strength parameters for design. A study investigating shallow first-time failures in clay cut slopes due to seasonal stress cycles has been undertaken using a validated numerical model capable of capturing seasonal ratcheting and progressive failure. It is shown that fully softened strength criteria are inappropriate for the assessment of shallow first-time failures due to seasonal ratcheting and that slopes at angles between the material's fully softened and residual friction angle may be at risk of failure in the future due to this behaviour. However, adopting residual strength parameters will likely result in overly conservative solutions considering the required design life of geotechnical assets. It is shown that the strain softening behaviour of clay defines the rate of strength deterioration and the operational life of engineered slopes. While general guidelines for analysis considering shallow first-time failures in clay cut slopes are made, detailed understanding of a material's strain-softening behaviour, the magnitude and rate of strength reduction with strains, is needed to establish strength criteria for limit equilibrium analysis.
\end{abstract}

Keywords: Cut Slope Stability; Seasonal Ratcheting; Progressive Failure of Clay; Numerical Modelling; Design Life.

Accepted manuscript: This document presents the accepted version of the manuscript. The final version may be subject to additional copy editing and typesetting. This manuscript version is made available under the CC BY 4.0 license: https://creativecommons.org/licenses/by/4.0/. The final published work is available from the Institution of Civil Engineers: https://doi.org/10. 1680/jgeen.21.00125.

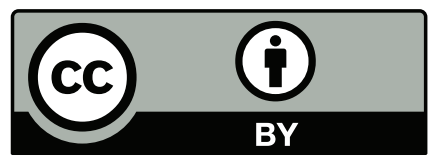

\section{Reference:}

Postill, H., Helm, P.R., Dixon, N., El-Hamalawi, A., Glendinning, S. and Take W.A. (2021). Strength parameter selection framework for evaluating the design life of clay cut slopes. Proc Inst Civ Eng - Geotechnical Engineering. Published online ahead of print. https://doi.org/10. 1680/jgeen.21.00125

\section{Data used in publication:}

Helm, P.R., Postill, H., Dixon, N., El-Hamalawi, A., Glendinning, S. and Take, W.A. (2021). Dataset: Strength parameter selection framework for evaluating the design life of clay cut slopes. Newcastle University. https://doi.org/10.25405/data.ncl.16598672 


\section{Contents}

1 Introduction 1

2 Seasonal Ratcheting: Numerical Model Validation 2

3 Numerical Modelling Methodology 3

3.1 Material Properties and Behaviour . . . . . . . . . . . . . . 3

3.2 Initial Conditions and Slope Formation . . . . . . . . . . . . . 7

4 Characterising Seasonal Ratcheting Behaviour $\quad 8$

4.1 Defining Operational Failure . . . . . . . . . . . . . . . . . . . 8

4.2 Residual Factor and Mobilised Friction Angle . . . . . . . . . . . . . . . . 11

5 Results of Numerical Analyses $\quad 12$

5.1 Effect of Slope Geometry and Strain-Softening Relationship . . . . . . . . . . 12

5.2 Effect of Slope Height . . . . . . . . . . . . . . . . . . . 16

5.3 Design Parameters to Achieve a Target Life . . . . . . . . . . . . . . . . 19

6 Discussion $\quad 22$

6.1 Effect of Slope Angle and Height . . . . . . . . . . . . . . . . . 22

6.2 Effect of Strain-Softening . . . . . . . . . . . . . . . . . . 23

6.3 Hydrology . . . . . . . . . . . . . . . . . . . . . . . . . . . . . . . . . . .

6.4 Other Considerations . . . . . . . . . . . . . . . . . . . . . . 24

7 Conclusions $\quad 26$

8 Acknowledgements $\quad 27$

9 References $\quad 28$

A1 Appendix: Numerical Modelling Framework 32

\section{List of Tables}

1 Mechanical properties for Kaolin (after Postill et al., 2020). . . . . . . . . . . 5

2 Kaolin Hydrogeological parameters (after Al-Tabbaa and Wood, 1987; and Postill et al., 2020). . . . . . . . . . . . . . . . . 5 


\section{List of Figures}

1 Typical mesh, boundary conditions and geometry. . . . . . . . . . . . 4

2 Strain-softening relationships (Cekerevac and Laloui, 2004). . . . . . . . . . . 6

3 Initial stress conditions prior to application of seasonal boundary conditions (after Postill et al., 2020); a) overconsolidation ratio; b) $K 0$; c) vertical and horizontal stresses. . . . . . . . . . . . . . . . . . .

4 Schematic plot showing seasonal ratcheting and progressive failure movement characteristics for an $8.65 \mathrm{~m}$ high $28.4^{\circ}$ slope; a) target pore water pressure cycles at mid-slope surface; b) slope surface displacements corresponding to mid-point of final failure surface, see Figure 6 for quantitative model data; c) reciprocal of velocity of net annual displacement at slope surface corresponding to mid-point of final failure surface when net movement is outward and downwards. . . . . . . . . . . . . . . . . .

5 Schematic deterioration curve and point of operational failure: a) reciprocal of velocity of net annual displacement at the slope surface corresponding to the centre of the failed region when net movement is outward and downwards and fitted curve; b) slope surface net displacements in an annual cycle corresponding to mid-point of final failure surface; c) slope surface net cumulative displacements in an annual cycle corresponding to mid-point of final failure surface d) residual factor calculated along final failure surface. . . . . . . . . .

6 Slope surface displacements corresponding to the mid-point of the final failure surface against number of annual cycles for different slope angles, strainsoftening curve (A); a) horizontal displacements; b) vertical displacements. . . 12 a) to e) Failure surfaces for different slope angles - strain-softening curve (A). .

8 Deterioration curves and points of operational failure for different slope geometries - strain-softening curve (A); a) reciprocal of velocity of net annual displacement at slope surface corresponding to mid-point of final failure surface when net movement is outward and downwards; b) fitted deterioration curve and point of operational failure. . . . . . . . . . . .

9 Results for different slope geometries and strain-softening relationships; a) number of annual cycles to operational failure for different slope angles; b) residual factor at operational failure against slope angle; c) residual factor at operational failure against number of annual cycles to operational failure. . . .

10 Residual factor on a critical shear surface at operational failure $-8.65 \mathrm{~m}$ high $28.4^{\circ}$ slopes; a) strain-softening curve (A); b) strain-softening curve (B); c) strain-softening curve $(\mathrm{C}) . \ldots \ldots \ldots \ldots$

11 Results for different slope geometries and heights; a) number of annual cycles to operational failure for different slope geometries; b) residual factor at operational failure against slope angle; c) residual factor at operational failure against number of annual cycles to failure. . . . . . . . . . . . . . .

12 Mobilised internal angle of friction at operational failure for different strainsoftening relationships, slope geometries, and heights; a) mobilised internal angle of friction at operational failure against slope angle; b) mobilised internal angle of friction at operational failure against number of annual cycles to failure. 20

13 Slope geometry, number of annual cycles to failure and mobilised friction angle at failure for strain-softening curve $(\mathrm{B}) \ldots \ldots \ldots \ldots$ 


\section{List of notation}

\begin{tabular}{|c|c|}
\hline$c^{\prime}$ & Cohesion \\
\hline$c_{f s}^{\prime}$ & Fully softened cohesion \\
\hline$c_{p}^{\prime}$ & Peak cohesion \\
\hline$c_{r}^{\prime}$ & Residual cohesion \\
\hline$e$ & Void ratio \\
\hline$G$ & Shear modulus \\
\hline$K$ & Bulk modulus \\
\hline$K_{r}^{a}$ & Unsaturated hydraulic conductivity of air phase \\
\hline$K_{r}^{w}$ & Unsaturated hydraulic conductivity of water phase \\
\hline$K_{\text {sat }}$ & Saturated hydraulic conductivity \\
\hline$K_{\text {sat }}^{h}$ & Horizontal saturated hydraulic conductivity \\
\hline$K_{\text {sat }}^{v}$ & Vertical saturated hydraulic conductivity \\
\hline$K 0$ & Coefficient of earth pressure at rest \\
\hline$l$ & Nonlocal internal length parameter \\
\hline$m$ & van Genuchten fitting parameter, $1-1 / n$ \\
\hline$n$ & van Genuchten fitting parameter \\
\hline$O C R$ & Overconsolidation ratio \\
\hline$R$ & Residual factor \\
\hline$r$ & Distance between target $\left(x_{n}\right)$ and nonlocal strain reference $\left(x_{n}^{\prime}\right)$ points \\
\hline$S_{e}$ & Effective saturation \\
\hline$S_{w}$ & Degree of (wetting) saturation \\
\hline$S_{w}^{r}$ & Residual wetting saturation \\
\hline$s$ & Matric suction \\
\hline$u_{a}$ & Pore air pressure \\
\hline$u_{w}$ & Pore water pressure \\
\hline$V_{w}$ & Nonlocal weighted volume \\
\hline$x_{n}$ & Target nonlocal strain point \\
\hline$x_{n}^{\prime}$ & Surrounding nonlocal strain reference points \\
\hline$\alpha$ & van Genuchten fitting parameter \\
\hline$\Delta \varepsilon^{p s}$ & Local plastic shear strain \\
\hline$\Delta \varepsilon_{j}^{p s}, j=1,3$ & Principal local plastic shear strain increments \\
\hline$\Delta \varepsilon_{m}^{p s}$ & $\frac{1}{3}\left(\Delta \varepsilon_{1}^{p s}+\Delta \varepsilon_{3}^{p s}\right)$ \\
\hline$\varepsilon_{p}^{*}$ & Nonlocal plastic strain \\
\hline$\theta$ & Slope angle \\
\hline$\kappa$ & Gradient of the swelling line \\
\hline$\Lambda$ & Inverse velocity \\
\hline$\lambda$ & Gradient of the normal consolidation line \\
\hline$\mu$ & Poisson's ratio \\
\hline$\nu$ & Specific volume \\
\hline$\nu_{\kappa}$ & Specific volume at reference pressure following the swelling line \\
\hline
\end{tabular}




$\begin{array}{ll}\nu_{\lambda} & \text { Original specific volume at reference pressure } \\ \sigma & \text { Total stress } \\ \sigma^{\prime} & \text { Effective stress } \\ \sigma_{B}^{\prime} & \text { Bishop's generalised effective stress } \\ \sigma_{h}^{\prime} & \text { Horizontal effective stress } \\ \sigma_{v}^{\prime} & \text { Vertical effective stress } \\ \sigma_{r e f} & \text { Reference pressure } \\ \tau & \text { Shear stress } \\ \tau_{\text {current }} & \text { Current shear strength on ultimate failure surface } \\ \tau_{\text {peak }} & \text { Peak shear strength on ultimate failure surface } \\ \tau_{\text {residual }} & \text { Residual shear strength on ultimate failure surface } \\ \phi^{\prime} & \text { Friction angle } \\ \phi_{c s}^{\prime} & \text { Critical state friction angle } \\ \phi_{f s}^{\prime} & \text { Fully softened friction angle } \\ \phi_{m}^{\prime} & \text { Mobilised friction angle } \\ \phi_{p}^{\prime} & \text { Peak friction angle } \\ \phi_{r}^{\prime} & \text { Residual friction angle } \\ \omega^{\prime} & \text { Nonlocal weighting function }\end{array}$




\section{Introduction}

Design of engineered clay cut slopes is conventionally conducted through limit equilibrium analysis with material properties adopted based on critical failure mechanisms. For deep-seated ( $>2 \mathrm{~m}$ deep) first-time failures in over-consolidated high-plasticity clay cut slopes, Chandler and Skempton (1974) and Skempton (1984) proposed fully softened drained strength parameters be adopted. These parameters were derived from back-analysis, representing the average mobilised strength along failure surfaces.

The deep-seated failures considered by Chandler and Skempton (1974) occurred due to postexcavation negative excess pore water pressure dissipation and progressive failure, with ultimate failure occurring around 40-80 years after excavation. As such, the failure mechanism being investigated defines the selection of strength parameters to determine stability. Therefore, fully softened strength criterion for limit equilibrium analysis of long-term stability is only acceptable if the mechanism driving failure is deep-seated and caused by pore water pressure dissipation. If the design life of the slope exceeds the time taken for pore water pressure dissipation or a different failure mechanism is dominant, fully softened strength design parameters may be inappropriate.

Geotechnical infrastructure and earthworks constructed for UK highways and the planned earthworks for UK High Speed 2 (HS2) can have design lives of up to 120 years (HS2 Ltd, 2017; Highways England, 2020). On the UK rail network, some assets are nearing or have significantly exceeded this age (Skempton, 1995; Network Rail, 2018). Assets intended to remain operational for this duration must be designed considering time dependent deep-seated failure mechanisms. In addition, long-term deterioration resulting from seasonal wetting and drying cycles that cause irrecoverable plastic deformations, leading to strain accumulation and progressive strength reduction (i.e. seasonal ratcheting) must also be considered as this can lead to shallow first-time failure mechanisms (Take and Bolton, 2011; Postill et al., 2020). These shallow failures in clay cut slopes forming part of the UK rail network are common and occur decades after equilibration of construction related negative excess pore water pressures. These failures evidence the significance of such shallow weather driven deterioration processes. Currently, there is little guidance for designers regarding material property selection for the assessment of shallow first-time failures in clay slopes due to seasonal stress cycles.

This paper presents a numerical study investigating first-time failures in high-plasticity clay slopes driven by seasonal ratcheting (Take and Bolton, 2011; Postill et al., 2020). A validated numerical model (Postill et al., 2020) was used to investigate the effect of material softening relationships indicative of different plasticity clays and slope geometry on failure rate and trends in behaviour. From the results presented, the design life implications and material property selection for use in conventional limit equilibrium stability analysis for shallow first-time failures in clay cut slopes have been discussed and recommendations made. 


\section{Seasonal Ratcheting: Numerical Model Validation}

This work utilises the modelling approach developed by Postill et al. (2020) in FLAC TwoPhase flow (Itasca, 2011) to further develop understanding of seasonal ratcheting in overconsolidated clay slopes. A coupled hydrogeological-mechanical numerical model with strainsoftening behaviour has been validated against physical modelling of clay cut slopes subjected to seasonal cycles of wetting and drying. The approach captures unsaturated behaviour using Bishop's generalised effective stress to describe mechanical behaviour coupled with an unsaturated flow model using a soil water retention curve (van Genuchten, 1980) to describe hydrogeological behaviour. A nonlocal Mohr-Coulomb strain-softening constitutive model was adopted to capture progressive failure. Postill et al. (2020, 2021) have shown this numerical modelling approach can replicate the hydrogeological and mechanical behaviour of seasonal ratcheting and explain strength deterioration of soils subjected to repeated seasonal stress cycles.

Complete description of the analyses, the implementation of a nonlocal strain-softening model and the material relationships used are described by Postill et al. (2020) and are summarised in the appendix. 


\section{Numerical Modelling Methodology}

This study focuses on the effects of slope geometry and strain-softening behaviour on seasonal ratcheting, using numerical analyses with different geometries and strain-softening relationships. Annual cyclic boundary conditions were imposed by a wetting/drying flux across the toe, slope, and crest of the model which in turn drove pore water pressure cycles within the model.

At the end of winter within each modelled annual cycle, surface pore pressures approach $0 \mathrm{kPa}$ and at the end of summer they approach $-40 \mathrm{kPa}$ to replicate the behaviour from the centrifuge modelling (Take and Bolton, 2011; Postill et al., 2020). Typical mesh configuration and boundary conditions are shown in Figure 1. The material and slope geometry were selected due to the availability of high quality hydrological and mechanical data from centrifuge modelling (Take, 2003; Take and Bolton, 2011) which allowed a validated numerical model to be developed (Postill et al., 2020) which is used in this work. This study is presented in two sections; firstly, slope geometries $8.65 \mathrm{~m}$ high at angles from $40.9^{\circ}$ to $15.1^{\circ}$, were analysed for three different strain-softening relationships. Secondly, using a single strain-softening relationship, slopes of different angles and heights, $5.0 \mathrm{~m}\left(59.0^{\circ}\right.$ to $\left.21.0^{\circ}\right), 8.65 \mathrm{~m}\left(40.9^{\circ}\right.$ to $\left.15.1^{\circ}\right)$ and $12.0 \mathrm{~m}\left(33.7^{\circ}\right.$ to $16.7^{\circ}$ ) high were analysed. A total of 63 analyses were undertaken and, with the exception of the softening relationships, the mechanical and hydrogeological properties, initial stresses, and magnitude of seasonal stress cycles imposed remained constant.

Current practice considers serviceability and ultimate limit state design criterion (BSI, 2004) intended to ensure the minimisation of deformations, and the avoidance of failure within the design life of the asset. If either the serviceability and/or the ultimate limit states are exceeded, the performance of the asset is no longer satisfactory. Within the context of this study, the time when these criteria are no longer met is defined as the operational life of the asset and is based on monitored displacements across the slope surface.

\subsection{Material Properties and Behaviour}

The modelled material is an idealised soil representative of over-consolidated clays. The strength and stiffness behaviour were derived from a high-plasticity clay (Sivakumar et al., 2009) with low swelling potential (Sridharan et al., 1973; Wang and Siu, 2006; Farrokhpay et al., 2016) that exhibits strain-softening behaviour (Cekerevac and Laloui, 2004).

A nonlocal strain-softening Mohr-Coulomb model was adopted where friction angle and cohesion are used to define shear strength at different plastic strains (Galavi and Schweiger, 2010; Summersgill et al., 2017a, 2018; Postill et al., 2020, 2021). The soil stiffness is made a function of specific volume that changes with stress to allow the effect of unloading during excavation and shrink-swell cycles on stiffness to be replicated. The adopted model along with a detailed 

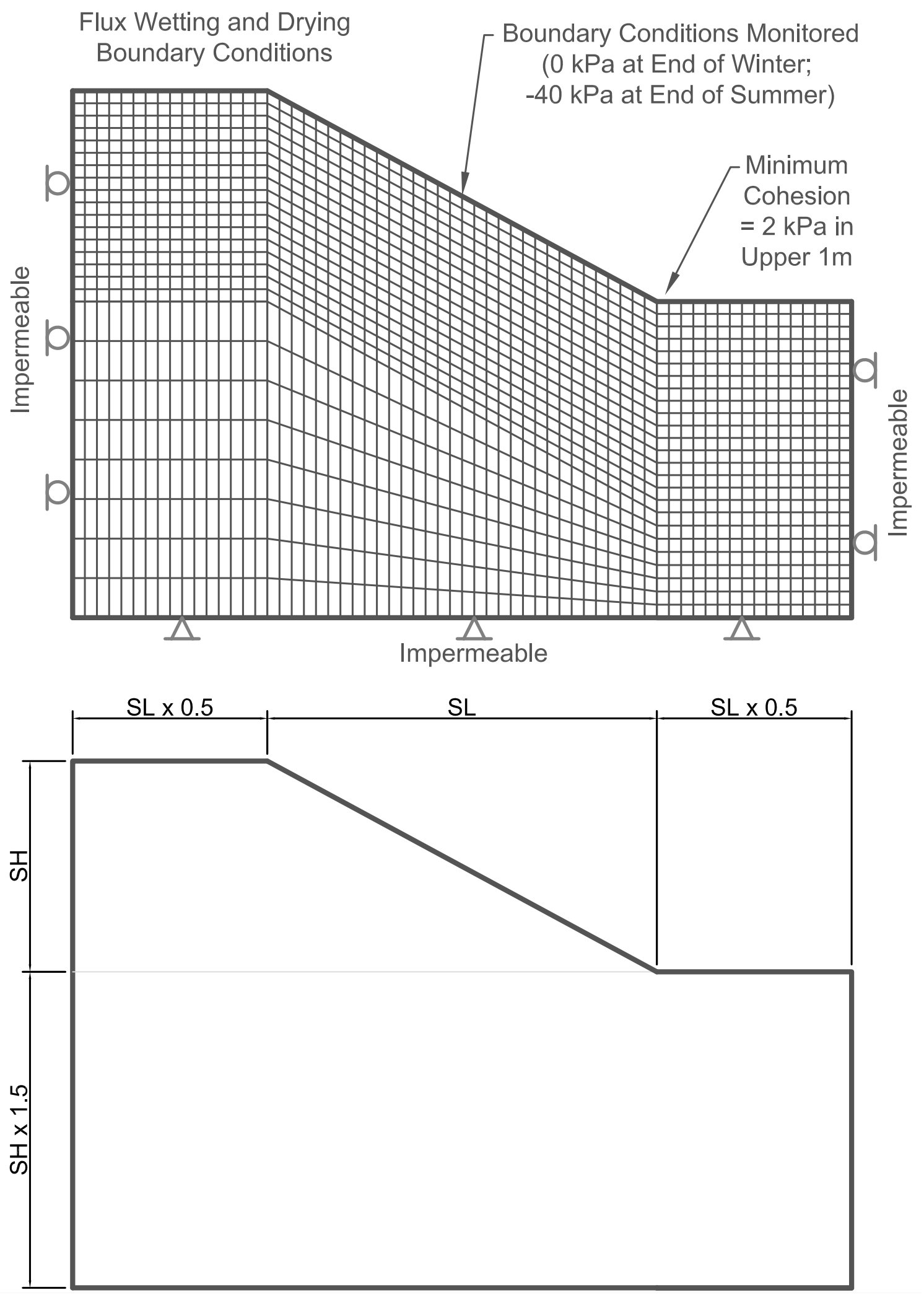

Figure 1: Typical mesh, boundary conditions and geometry. 
description of the material and validation of the behaviour can be found in Postill et al. (2020) and the appendix. The material properties are summarised in Table 1 and Table 2

Table 1: Mechanical properties for Kaolin (after Postill et al., 2020).

\begin{tabular}{ll}
\hline Parameter & Value \\
\hline Peak nonlocal plastic strain & 0.05 \\
Fully softened nonlocal plastic strain & 0.15 \\
Residual nonlocal plastic strain (Curve B) & 0.80 \\
Residual nonlocal plastic strain (Curve C) & 0.40 \\
Internal length parameter, $l(\mathrm{~m})$ & 0.50 \\
Peak cohesion, $c_{p}^{\prime}(\mathrm{kPa})$ & 6.25 \\
Fully softened cohesion, $c_{f s}^{\prime}(\mathrm{kPa})$ & 0.00 \\
Residual cohesion, $c_{r}^{\prime}(\mathrm{kPa})$ & 0.00 \\
Peak friction, $\phi_{p}^{\prime}\left({ }^{\circ}\right)$ & 24.0 \\
Fully softened friction, $\phi_{f s}^{\prime}\left({ }^{\circ}\right)$ & 22.0 \\
Residual friction, $\phi_{r}^{\prime}\left({ }^{\circ}\right)$ & 12.0 \\
Unit weight $\left(\mathrm{kN} / \mathrm{m}^{3}\right)$ & 17.9 \\
Slope of the normal consolidation line, $\lambda$ & 0.25 \\
Slope of the swelling line, $\kappa$ & 0.05 \\
Reference pressure, $\sigma_{r e f}(\mathrm{kPa})$ & 1.00 \\
Specific volume at $\sigma_{r e f}, \nu_{\lambda}$ & 3.55 \\
Poisson's ratio, $\mu$ & 0.35 \\
Bulk modulus, $K(\mathrm{kPa})^{*}$ & $\frac{\nu \cdot \sigma^{\prime}}{\kappa} ; \mathrm{min} .2000 \mathrm{kPa}$ \\
Shear modulus, $G(\mathrm{kPa})$ & $\frac{3(1-2 \mu)}{2(1+\mu)} \cdot K$ \\
\hline
\end{tabular}

${ }^{*} \nu=$ specific volume and $\sigma^{\prime}=$ effective stress $(\mathrm{kPa})$

Table 2: Kaolin Hydrogeological parameters (after Al-Tabbaa and Wood, 1987; and Postill et al., 2020).

\begin{tabular}{ll}
\hline Parameter & Value \\
\hline van Genuchten parameter, $\alpha(\mathrm{kPa})$ & 7000 \\
van Genuchten parameter, $n$ & 1.85 \\
van Genuchten parameter, $m$ & $1-(1 / n) \approx 0.46$ \\
Vertical saturated hydraulic conductivity, $K_{\text {sat }}^{v}(\mathrm{~m} / \mathrm{s})$ & $0.53 e^{3.16} \times 10^{-9 *}$ \\
Horizontal saturated hydraulic conductivity, $K_{\text {sat }}^{h}(\mathrm{~m} / \mathrm{s})$ & $1.49 e^{2.03} \times 10^{-9 *}$ \\
\hline${ }^{*} e=$ void ratio &
\end{tabular}

Over-consolidated clay undergoes post peak strength reduction due to dilation as a function of shear strains. Once this dilation is completed, shear strains occur at constant volume (the critical state), $\phi_{c s}^{\prime}$. Terminology adopted for post peak strength varies however. For example the term fully softened strength was employed by Skempton $(1964,1984)$ which was defined as 
being equal to the peak strength of normally consolidated remoulded clay (Skempton, 1970). Although differing in definition and value, the fully softened strength, due to its ease of determination, was suggested by Skempton (1970) as an approximation of the critical state. This, combined with the recommended use of fully softened strength in slope stability analyses for first-time failure in the literature (see for example Stark et al., 2005; Castellanos et al., 2016) has led to its adoption here. As such, in this work, the softening of over-consolidated clay to a fully softened $\left(c_{f s}^{\prime}, \phi_{f s}^{\prime}\right)$ state is represented by a total reduction in the cohesive element of the Mohr-Coulomb envelope and a minor reduction in the frictional component occurring from peak to post peak.

In high-plasticity materials, subject to large displacements beyond critical state, significant particle reorientation and alignment can occur (Lupini et al., 1981) leading to strain-softening to residual strength, as seen in ring shear and reversal shear tests (Lupini et al., 1981; Mesri and Cepeda-Diaz, 1986; Dobbie, 1992). This is represented in the model by reductions in friction angle to residual at large plastic strains.

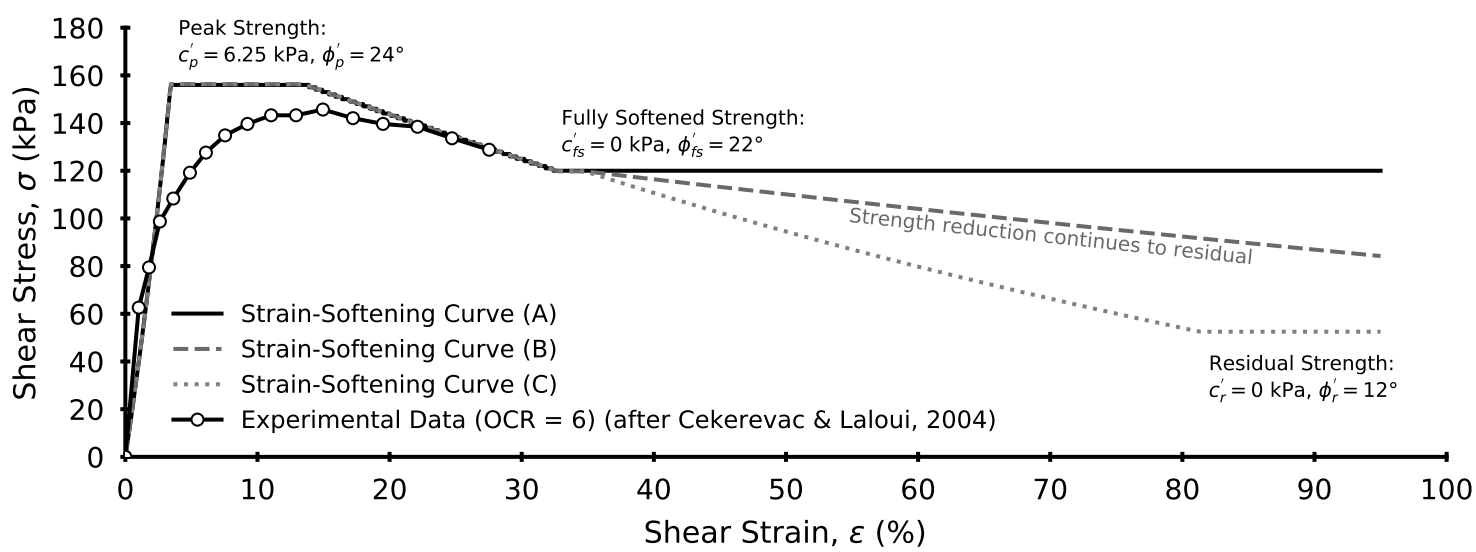

Figure 2: Strain-softening relationships (Cekerevac and Laloui, 2004).

Three strain-softening relationships were adopted to investigate how shearing behaviour influences seasonal ratcheting (see Figure 2 and Table 1). These data were obtained from a single element numerical model of a drained triaxial test (Postill et al., 2020), and were compared to experimental triaxial data (Cekerevac and Laloui, 2004). Strain-softening curve (A) includes the initial strength reduction post peak without further loss of strength at larger strains. This is representative of low to intermediate-plasticity over-consolidated clays and is intended as a baseline for comparison in the assessment of behaviour of the other softening curves.

Strain-softening curves (B) and (C) represent soils that undergo additional shear strength reduction to residual, representative of high-plasticity over-consolidated clays with differing rates of strength reduction from post peak to residual. This accounts for the variability in displacement required to reach residual strength.

The effective shear strength at shallow depths may reach very low values leading to excessive 
deformations. In practice this does not occur due to the presence of vegetation and so to avoid this numerical artefact, the fully softened and residual cohesion of the top $1 \mathrm{~m}$ of all models was limited to a minimum of $2 \mathrm{kPa}$ (Postill et al., 2020), as shown in Figure 1.

\subsection{Initial Conditions and Slope Formation}

To replicate stresses within over-consolidated natural clays (the overconsolidation ratio, $O C R$, is summarised in Figure 3a), a profile of coefficient of earth pressure at rest $(K 0)$ was derived from $O C R$ using the following: $K 0=\left(1-\sin \phi^{\prime}\right)(O C R)^{\sin \phi^{\prime}}$ (Mayne and Kulhawy, 1982). The resultant $K 0$ profile similar to that presented by Kovacevic et al. (2007) for excavations in stiff over-consolidated clay was adopted (see Figure $3 b$ ). The resultant depth dependent stress distribution prior to formation of the slope profile is summarised in Figure 3c.

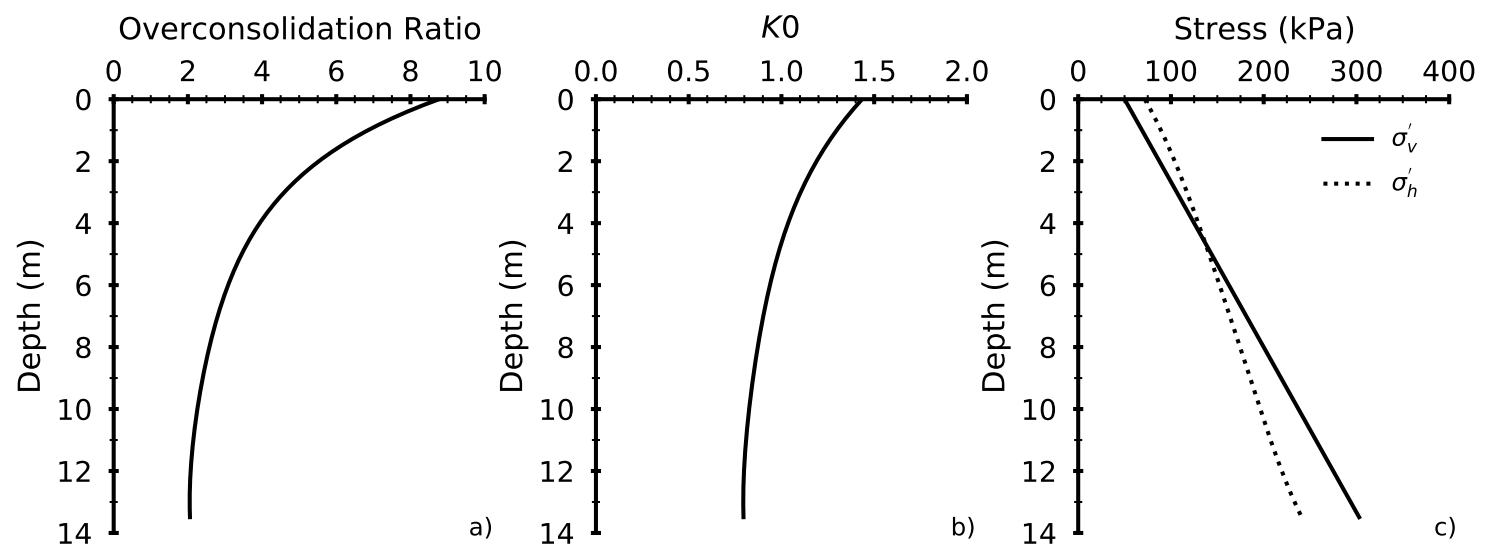

Figure 3: Initial stress conditions prior to application of seasonal boundary conditions (after Postill et al., 2020); a) overconsolidation ratio; b) $K 0$; c) vertical and horizontal stresses. 


\section{Characterising Seasonal Ratcheting Behaviour}

Annual wet/dry cycles, and resultant effective stress changes drive shrink-swell behaviour and the accumulation of plastic deformations causing strain-softening, stress redistribution and progressive failure (Take and Bolton, 2011; Postill et al., 2020; Rouainia et al., 2020). For a single slope model, Figure 4a shows target annual pore pressure cycles at the mid-slope surface where one year is characterised by a cycle from $0 \mathrm{kPa}$ (winter) to $-40 \mathrm{kPa}$ (summer) and then back to $0 \mathrm{kPa}$. Figure $4 \mathrm{~b}$ shows displacements typical of seasonal ratcheting behaviour driven by these stress changes. Figure $4 \mathrm{c}$ shows the reciprocal of slope velocity calculated from net annual displacement.

The reciprocal of velocity is used to define failure from a negative linear relationship with time (Saito, 1980; Petley et al., 2005). Figure 4c demonstrates deteriorating slope performance with time, moving from a stable to deteriorating state. As velocity increases, the reciprocal of velocity tends towards zero illustrating acceleration towards ultimate limit state failure.

As deformations accumulate, strength deterioration takes place in a developing shear zone beneath the slope, but at a rate that does not lead to a significant loss of performance affecting the overall stability of the slope (this is discussed and quantified in the following section).

Figure $4 \mathrm{~b}$ shows that after approximately 40 annual stress cycles, for this geometry the magnitude of seasonal displacements increases. This increase illustrates a reduction in strength and stiffness and a deterioration in slope stability (i.e. a given size of pore water cycle can generate larger displacements). In addition, larger deformations mean increased strains and an increased rate of strength reduction, a deterioration in slope stability and hence progressive failure (Skempton, 1964). This slope deterioration due to reduction in strength, results in a further performance reduction. This process is demonstrated by larger seasonal displacement cycles in Figure $4 \mathrm{~b}$ and by the reciprocal of velocity tending towards zero (and ultimate limit state failure) in Figure 4c.

\subsection{Defining Operational Failure}

The adopted definition of failure used here (operational failure) is the time when uncontrolled acceleration occurs (the inflection point on the $\Lambda$ vs time plot). The mobilised shear strength for the critical shear surface at failure is used to derive the minimum shear strength parameters for use in conventional slope stability analysis. A schematic diagram demonstrating this approach is shown in Figure 5. To illustrate the method, the failure time from Figure 5a has been plotted on Figures 5b, 5c and 5d. The failure time is derived based on the location of the inflection point of the inverse velocity fitting curve and correlates with the point in time where annual displacements show an increase in magnitude and cumulative displacements begin to increase as the rate of displacement increases. 

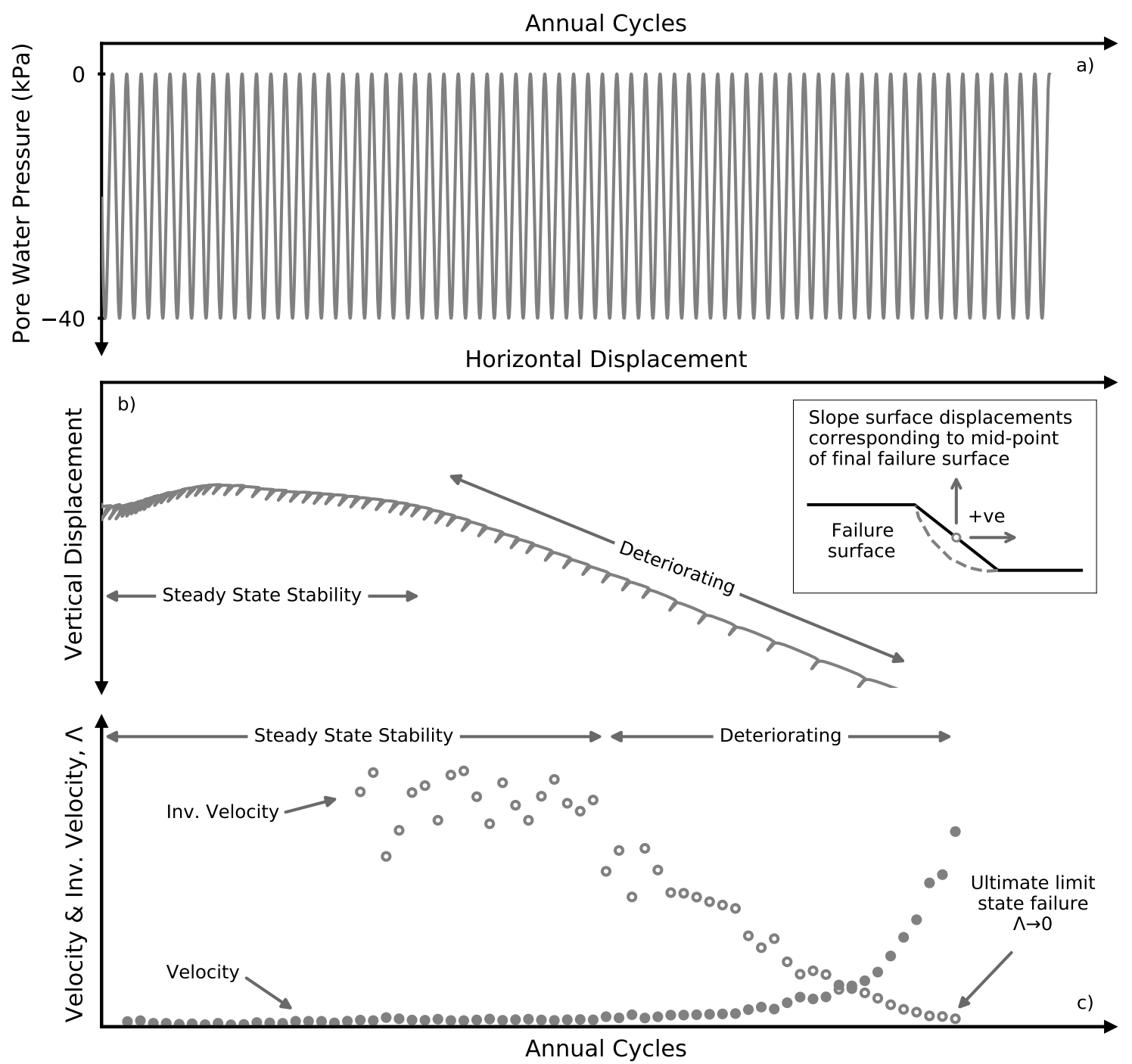

Figure 4: Schematic plot showing seasonal ratcheting and progressive failure movement characteristics for an $8.65 \mathrm{~m}$ high $28.4^{\circ}$ slope; a) target pore water pressure cycles at mid-slope surface; b) slope surface displacements corresponding to mid-point of final failure surface, see Figure 6 for quantitative model data; c) reciprocal of velocity of net annual displacement at slope surface corresponding to mid-point of final failure surface when net movement is outward and downwards. 


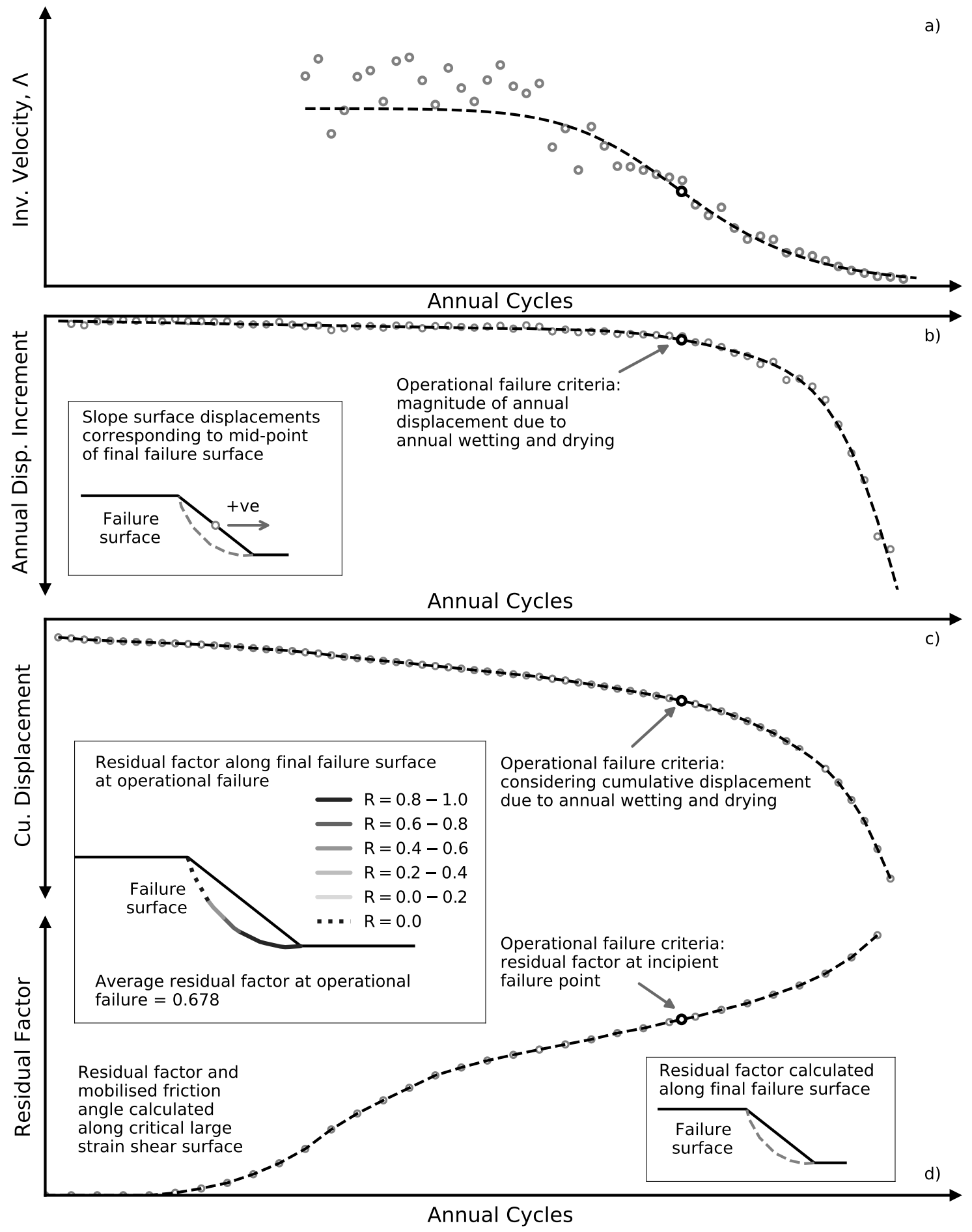

Figure 5: Schematic deterioration curve and point of operational failure: a) reciprocal of velocity of net annual displacement at the slope surface corresponding to the centre of the failed region when net movement is outward and downwards and fitted curve; b) slope surface net displacements in an annual cycle corresponding to mid-point of final failure surface; c) slope surface net cumulative displacements in an annual cycle corresponding to mid-point of final failure surface d) residual factor calculated along final failure surface. 


\subsection{Residual Factor and Mobilised Friction Angle}

To derive the average mobilised strength over time, the residual factor, $R$, (Skempton, 1964) for the critical failure surface was back calculated using Eqn. 1 and Eqn. 2.

$$
\begin{gathered}
\tau=c^{\prime}+\sigma^{\prime} \cdot \tan \left(\phi^{\prime}\right) \\
R=\frac{\tau_{\text {peak }}-\tau_{\text {current }}}{\tau_{\text {peak }}-\tau_{\text {residual }}}
\end{gathered}
$$

The critical failure surface was derived from observation of contour plots of plastic shear strains, where a region of elevated plastic shear strains indicated the location of the shear surface.

The residual factor was then derived for the critical failure surface for cycles prior to failure. A schematic representation of this is plotted in Figure $5 \mathrm{~d}$.

In addition to residual factor, mobilised friction angle $\left(\phi_{m}^{\prime}\right)$ at operational failure was derived as a design parameter and to illustrate the level of deterioration experienced by the slope, independent of the current stress state of the analysis at the point of calculation. $\phi_{m}^{\prime}$ was calculated by averaging the friction angle of the model zones located within the band of plastic shear strain defining the final failure surface.

At failure, the material strength will range from peak to residual along the critical failure surface (see Figure 5). Calculating an average residual factor or average mobilised angle of friction along the whole shear surface removes the spatial variability of the strength deterioration due to progressive failure predicted by the numerical analyses but produces strength parameters that are compatible with limit equilibrium analysis and back analysed failure data, and which can inform design. 


\section{Results of Numerical Analyses}

\subsection{Effect of Slope Geometry and Strain-Softening Relationship}

Figure $6 \mathrm{a}$ and Figure $6 \mathrm{~b}$ show progressive outward horizontal and downward vertical displacements of the slope surface corresponding to the centre of the failed region for analyses of differing geometries using strain-softening curve (A), which are characteristic of seasonal ratcheting.

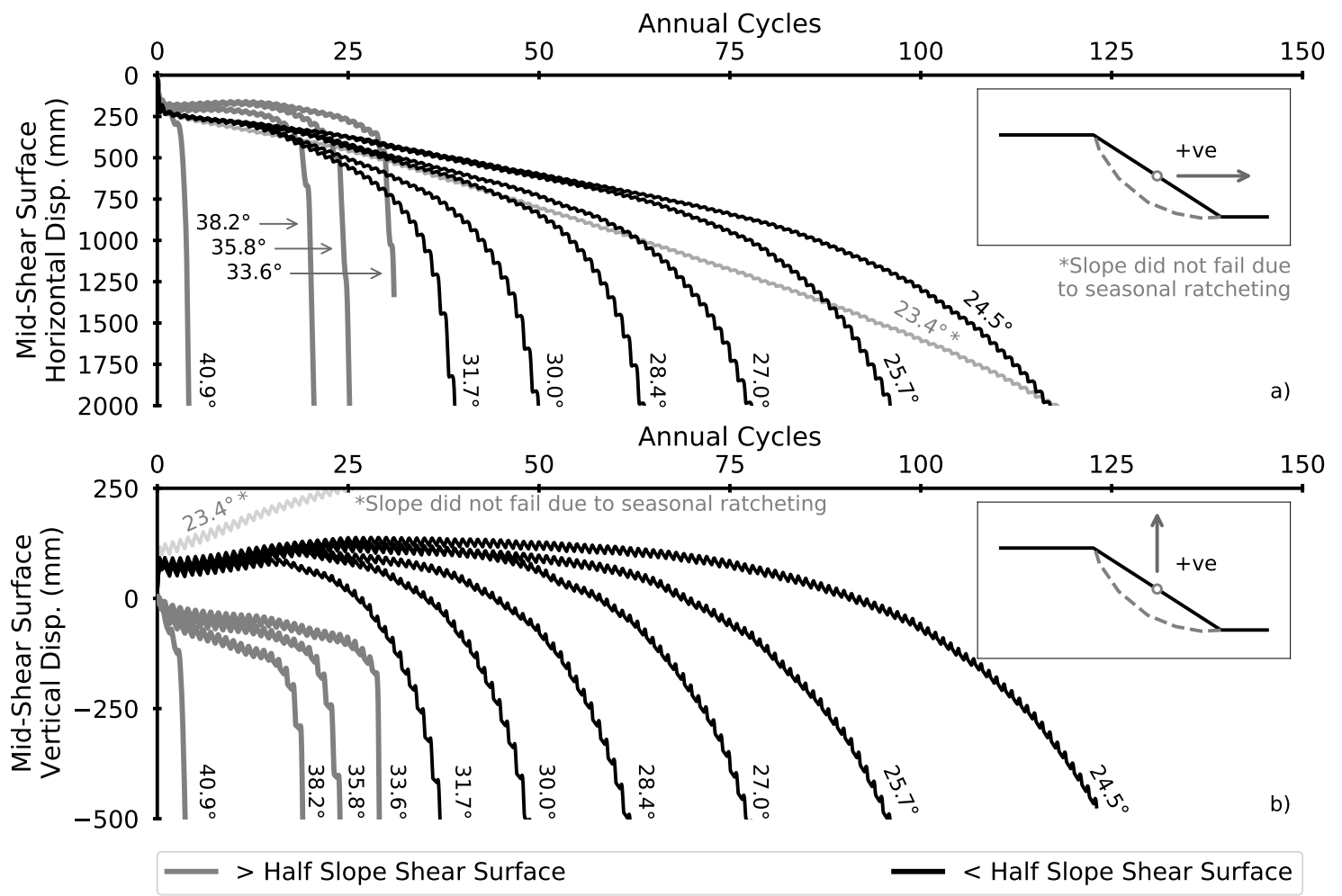

Figure 6: Slope surface displacements corresponding to the mid-point of the final failure surface against number of annual cycles for different slope angles, strain-softening curve (A); a) horizontal displacements; b) vertical displacements.

Figure 6 also shows that decreasing the slope angle increases the number of annual cycles required for failure. Slope angles from $40.9^{\circ}$ to $33.6^{\circ}$ (Figure 6) fail suddenly and failure surfaces include the majority of the slope length ( $>$ half the slope length), as shown in Figure 7. The second group of slopes, $31.7^{\circ}$ to $24.5^{\circ}$ have shorter failure surfaces $(<$ half the slope length) and failure was more gradual, with increasing numbers of cycles.

Slope angle $23.4^{\circ}$ diverges from the trends shown by the other analyses. Horizontal movements increase with number of annual cycles but do not accelerate to failure. Vertical displacements indicate swelling but show no sign of failure. Softening to minimum strength for the $23.4^{\circ}$ model occurred at the toe and within the near-surface of the slope. However, the model did not experience seasonal ratcheting or failure. The results indicate that the minimum internal angle of friction of the soil limits the geometry of slopes that are at risk of failure due to seasonal ratcheting. 
The minimum friction angle for analyses presented in Figure 6 was $22.0^{\circ}$ (the residual friction angle for softening curve A) and a slope of $23.4^{\circ}$ did not fail; the difference in these angles is attributed to the increased surface cohesion required to eliminate shallow failures in the surface elements of the numerical model. The failure surfaces predicted by the numerical analyses indicate the shallower the slope angle, the shallower and shorter the failure surface, see Figure 7.
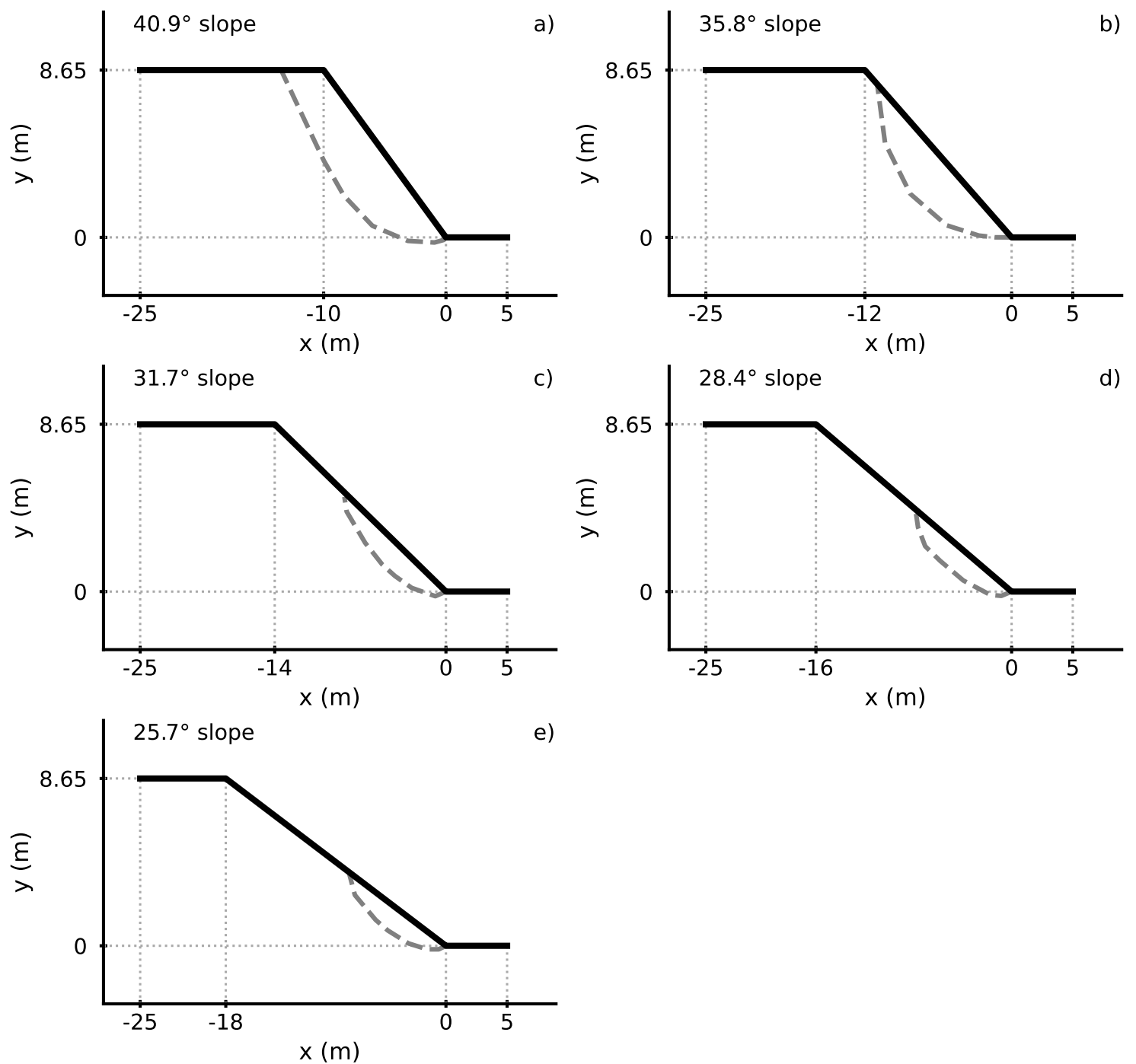

Figure 7: a) to e) Failure surfaces for different slope angles - strain-softening curve (A).

The reciprocal of velocity for the different slope geometries and time of operational failure are shown in Figure 8, illustrating the methodology previously presented. 

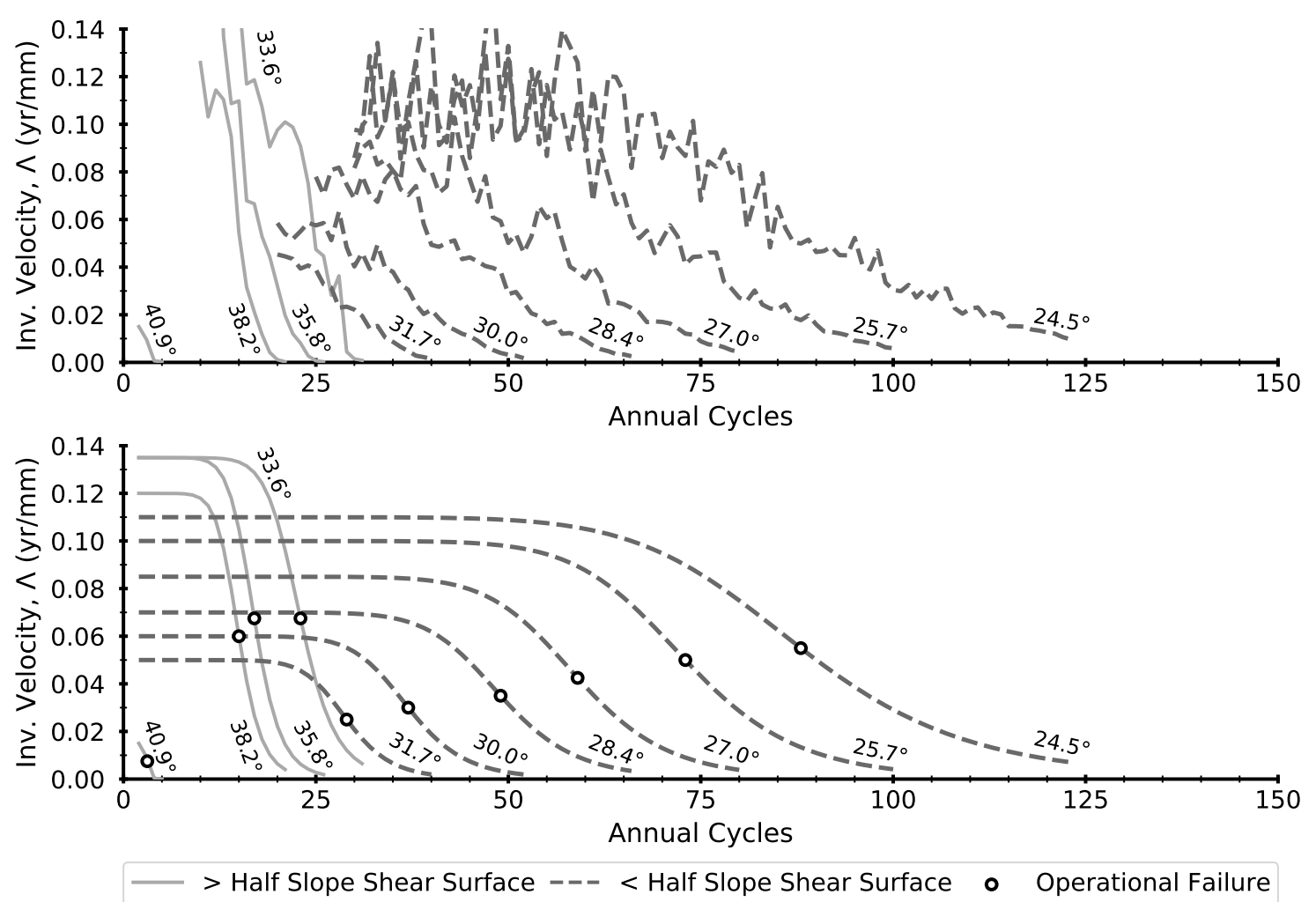

Figure 8: Deterioration curves and points of operational failure for different slope geometries strain-softening curve (A); a) reciprocal of velocity of net annual displacement at slope surface corresponding to mid-point of final failure surface when net movement is outward and downwards; b) fitted deterioration curve and point of operational failure.

The number of annual stress cycles to failure for different geometries and the three strainsoftening relationships along with the residual factor at operational failure are presented in Figure 9. 


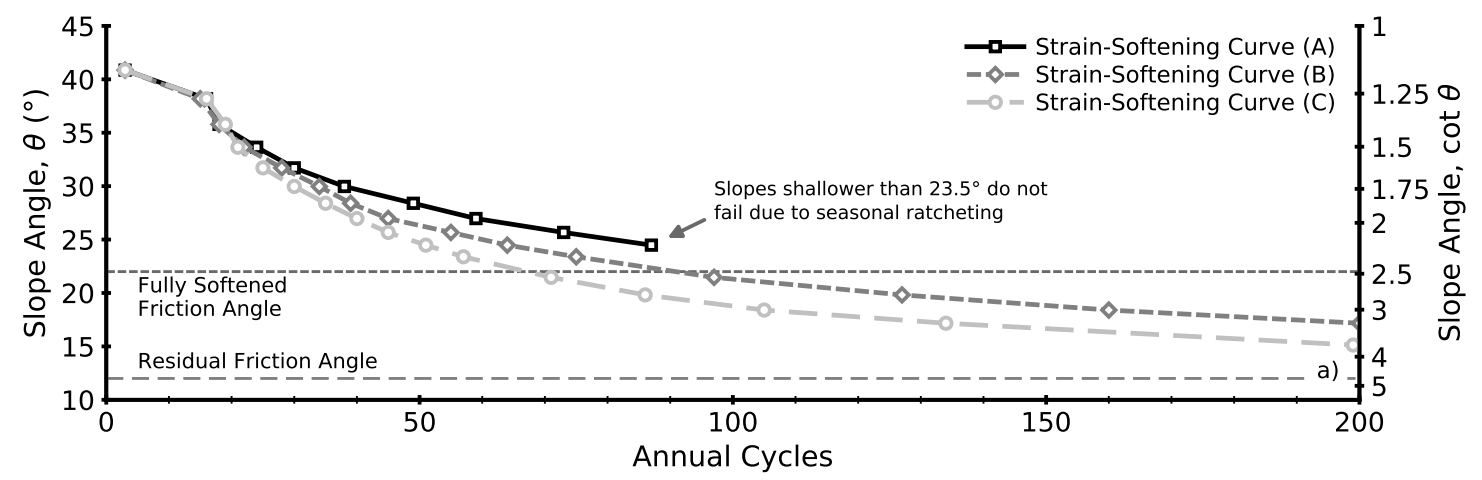

Slope Angle, $\cot \theta$
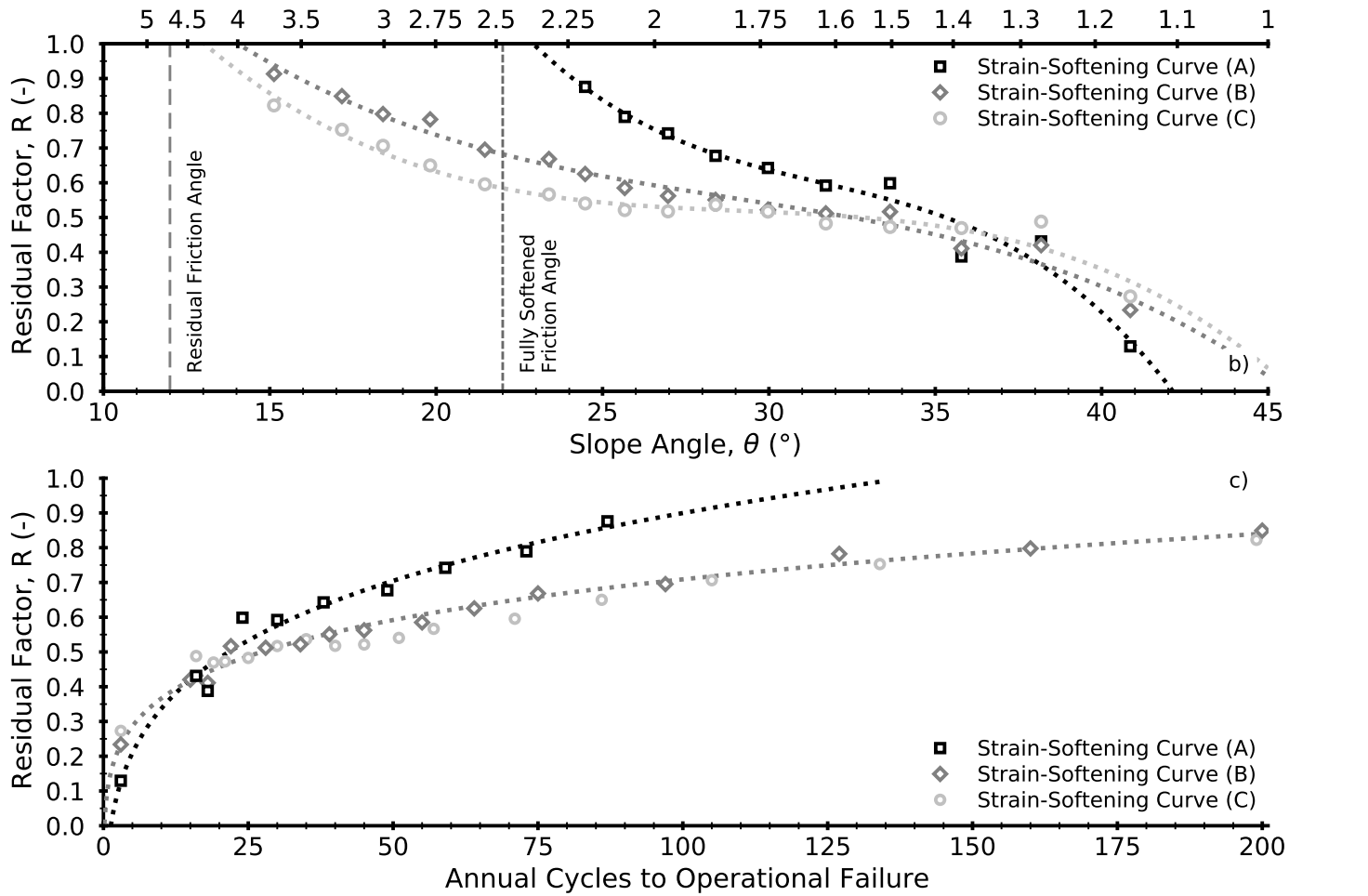

Figure 9: Results for different slope geometries and strain-softening relationships; a) number of annual cycles to operational failure for different slope angles; b) residual factor at operational failure against slope angle; c) residual factor at operational failure against number of annual cycles to operational failure.

Figure 9 shows two clear trends, associated with models that include strength reduction beyond fully softened to residual (strain-softening curves (B) and (C), representative of high-plasticity clays) and those that do not (i.e. curve (A), representative of low to intermediate-plasticity clays). As slope angles approach the minimum friction angle of the material $\left(22^{\circ}\right.$ for curve (A) and $12^{\circ}$ for curves (B) and (C)) the number of annual cycles required to cause deterioration to failure increases, with slopes constructed at the minimum friction angle not failing due to seasonal ratcheting. Figure 9a shows that the rate and magnitude of strength reduction significantly influences the number of annual stress cycles to failure for a given slope geometry.

Figure $9 \mathrm{~b}$ shows that slope angles greater than $35^{\circ}$ (steep slopes within this material with angles greater than approximately 1 in 1.5 ), require little strength reduction for failure to occur. All 
strain-softening curves exhibit the same behaviour for steep slopes, indicating peak strength dictates behaviour and once peak strength is mobilised, failure occurs. The primary failure mechanism for these steep slopes is not driven by seasonal ratcheting.

As the slope angle reduces $\left(<35^{\circ}\right)$, behaviour differs. For strain-softening curve $(\mathrm{C})$, the residual factor at failure for the same geometry slope is less than that of curve (B). As the rate of reduction of soil strength to residual increases, the mobilised strength at failure also increases, showing the significance of understanding the rate of strength reduction, as it influences the nature and rate of a slope failure due to seasonal ratcheting.

The rate of strength reduction also influences the depth, curvature, and length of failure surfaces for slopes of the same geometry. The numerical analyses predict deeper shear surfaces when strain-softening curve $(\mathrm{C})$ is employed compared to curves $(\mathrm{A})$ and $(\mathrm{B})$. The greater the rate and magnitude of strength reduction from post peak to residual, the greater the excess shear stress requiring redistribution during progressive failure, the more energy requiring dissipation and thus the deeper and longer the failure surface, see Figure 10. For strain-softening curves (B) and $(\mathrm{C})$, there are a group of slopes with angles less than the fully softened friction angle of $22^{\circ}$ where failure occurs. These failures are driven by seasonal ratcheting beyond the fully softened strength towards residual with a resultant increase in residual factor ( $R=0.6$, see Figure 9b) and a progressively larger degree of strength reduction required to trigger failure as slope angle decreases towards residual.

A significant increase in the number of stress cycles prior to failure can be achieved by small decreases in design slope angle. This can be seen in Figure 9b and Figure 9c which show the increased residual factor and hence softening required to trigger failure as slope angle decreases and in turn the commensurate increase in number of cycles to failure.

\subsection{Effect of Slope Height}

Three differing height slopes of varying angles were analysed using strain-softening curve (B) as shown in Figure 11. 


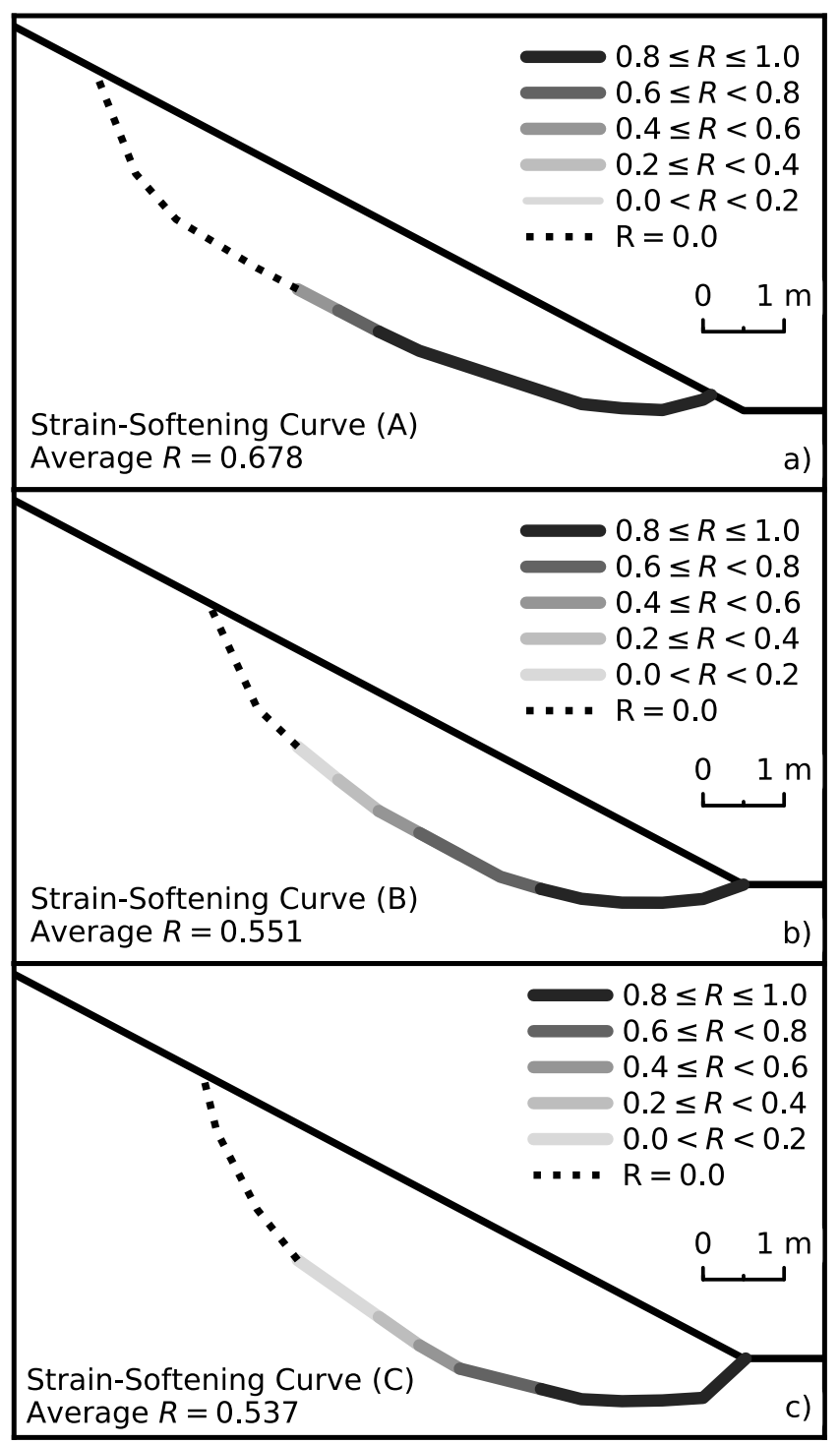

Figure 10: Residual factor on a critical shear surface at operational failure $-8.65 \mathrm{~m}$ high $28.4^{\circ}$ slopes; a) strain-softening curve (A); b) strain-softening curve (B); c) strain-softening curve (C). 


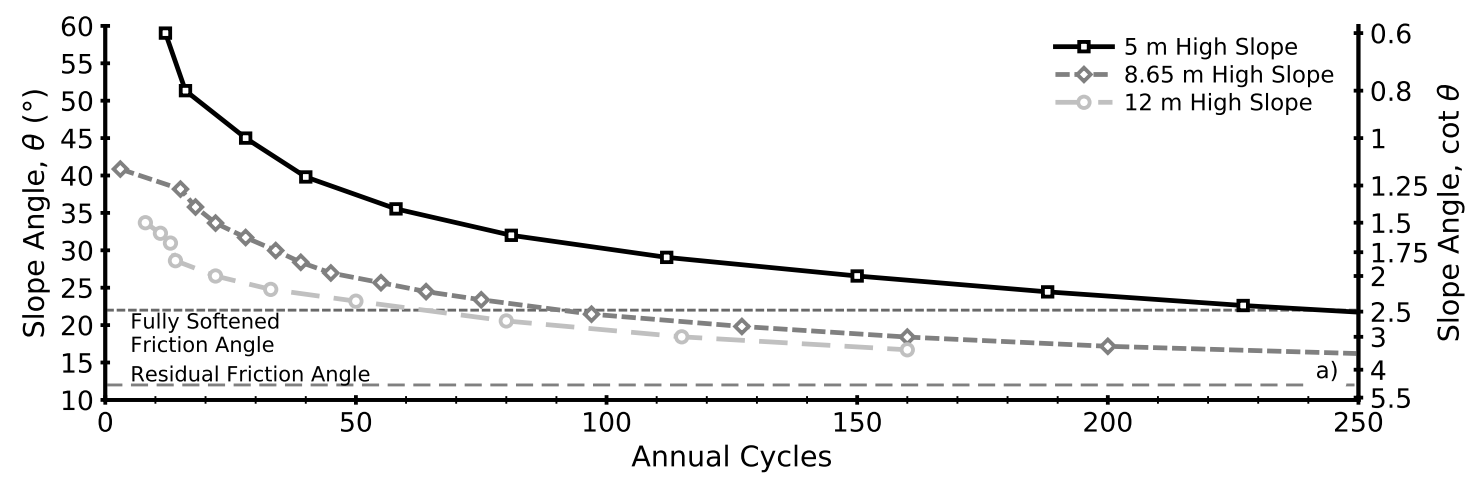

Slope Angle, $\cot \theta$
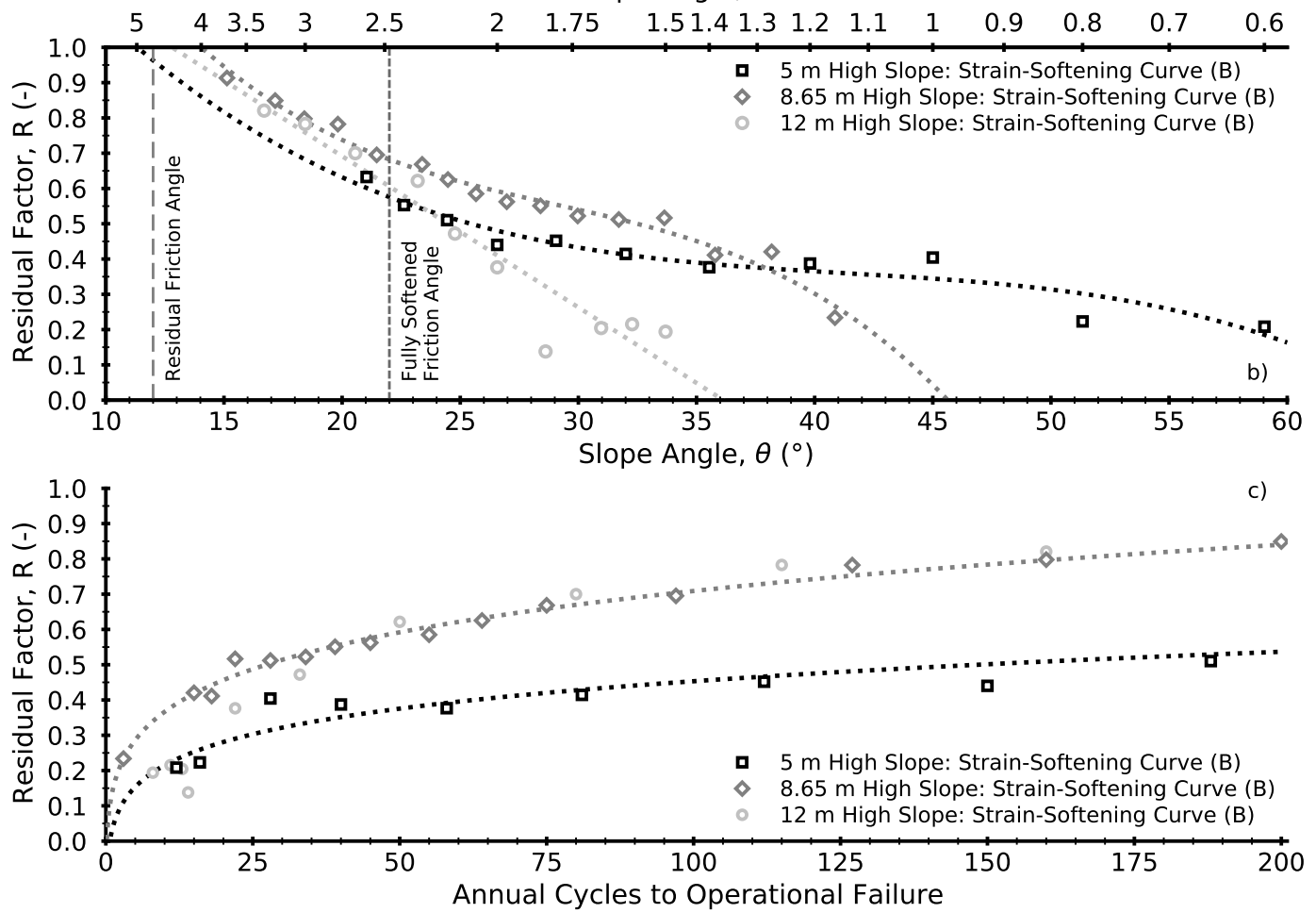

Figure 11: Results for different slope geometries and heights; a) number of annual cycles to operational failure for different slope geometries; b) residual factor at operational failure against slope angle; c) residual factor at operational failure against number of annual cycles to failure.

Figure 11a shows that steep angled, high slopes $\left(>35^{\circ}\right.$ and $\left.\geq 8.65 \mathrm{~m}\right)$ fail after a limited number of annual cycles, as their initial stability is marginal. However, $5 \mathrm{~m}$ high slopes remain stable for higher numbers of stress cycles even at steep angles. Failure in these cases is due to seasonal ratcheting.

Figure $11 \mathrm{~b}$ shows that for slope angles less steep than the fully softened friction angle, the strength reduction required for failure to occur for a given slope angle is independent of slope height. However, for slope angles greater than the fully softened friction angle, behaviour differs depending on slope height, where the lower the height, the greater the slope angle that will remain stable for the same number of annual cycles (e.g. from Figure 11c, for a design life of 75 years, a $5 \mathrm{~m}$ high slope would fail with a residual factor of 0.41 , corresponding to a maximum slope angle from Figure $11 \mathrm{~b}$ of $31^{\circ}$ and for slopes of 8.65 and $12 \mathrm{~m}$ this corresponds 
to residual factors at failure of 0.65 and slope angles of $23^{\circ}$ and $20^{\circ}$ respectively).

\subsection{Design Parameters to Achieve a Target Life}

The numerical analyses show that the residual friction angle of soil defines the minimum slope angle that is at risk of failure due to seasonal ratcheting. The results presented in Figure 9 and Figure 11 show the slope geometries investigated are in one of three categories; 1) slope geometries that fail when subjected to a small number of annual stress cycles requiring minimal strength reduction (failure not due to seasonal ratcheting); 2) slope geometries that require strength reduction to fail; and 3) slope geometries that experience significant strength reduction but where the number of annual stress cycles required for failure is far in excess of the design lives of typical engineered geotechnical assets (120 years).

Figure $12 \mathrm{a}$ and $12 \mathrm{~b}$ present the mobilised friction angles at failure (see Sections $4.1 \& 4.2$ and Figure 5) for all models except those representative of intermediate-plasticity clays (strainsoftening curve (A)). These results are summarised in Figure 13, presenting the relationships between slope geometry, design life and mobilised friction angle at failure. 

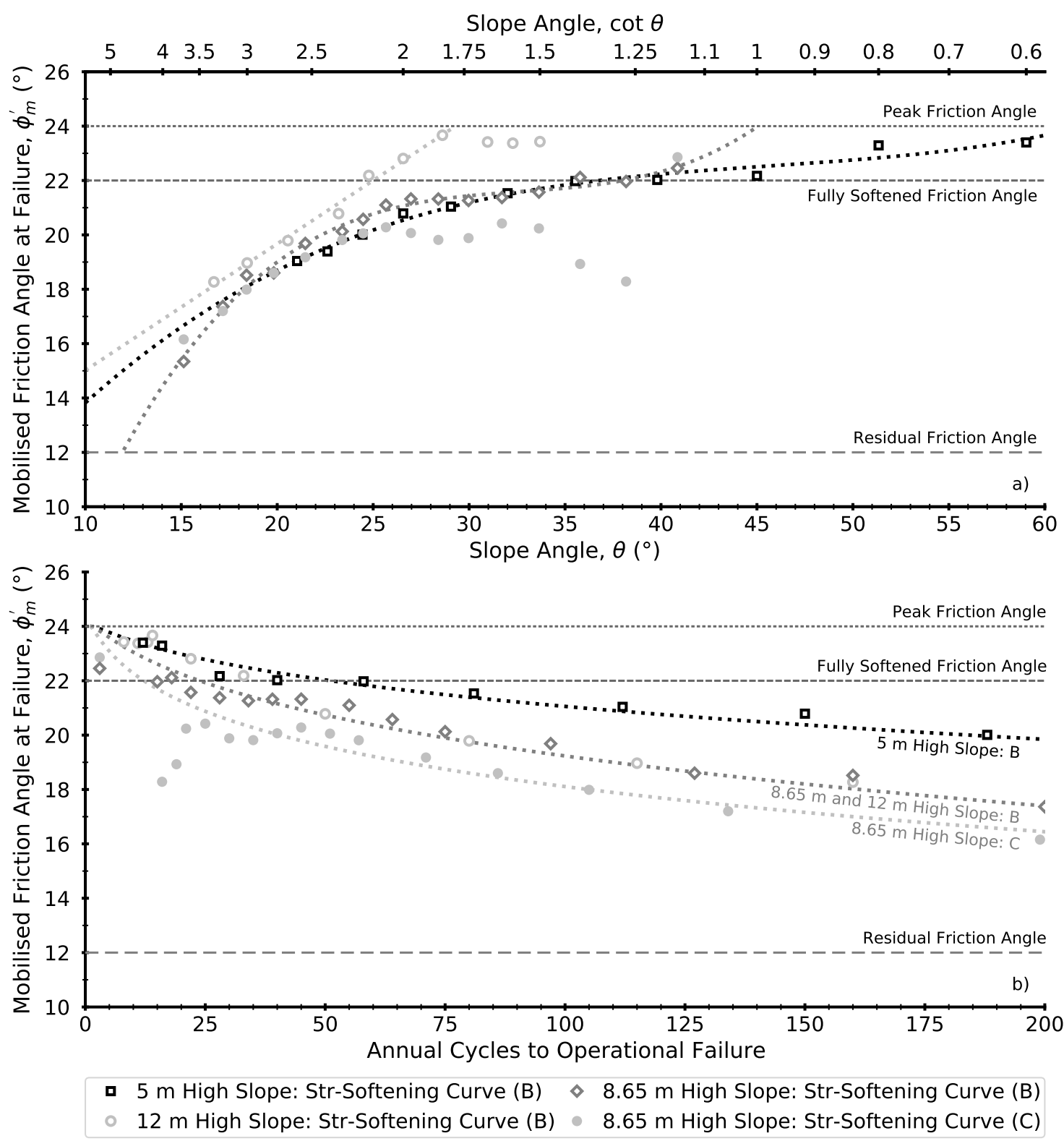

Figure 12: Mobilised internal angle of friction at operational failure for different strainsoftening relationships, slope geometries, and heights; a) mobilised internal angle of friction at operational failure against slope angle; b) mobilised internal angle of friction at operational failure against number of annual cycles to failure.

Figure 13 demonstrates an approach that could be used for rapid evaluation of the permissible slope geometry for a target design life (or conversely the remaining serviceable life of an existing slope of specified geometry). For example, a $10 \mathrm{~m}$ high slope, with a design life of 60 , 90 or 120 years should be constructed at $23.5^{\circ}, 21^{\circ}$ and $19^{\circ}$ respectively. This is an increase in slope horizontal length of $6.0 \mathrm{~m}$ to increase the design life from 60 to 120 years or $2.8 \mathrm{~m}$ for 90 to 120 years. 


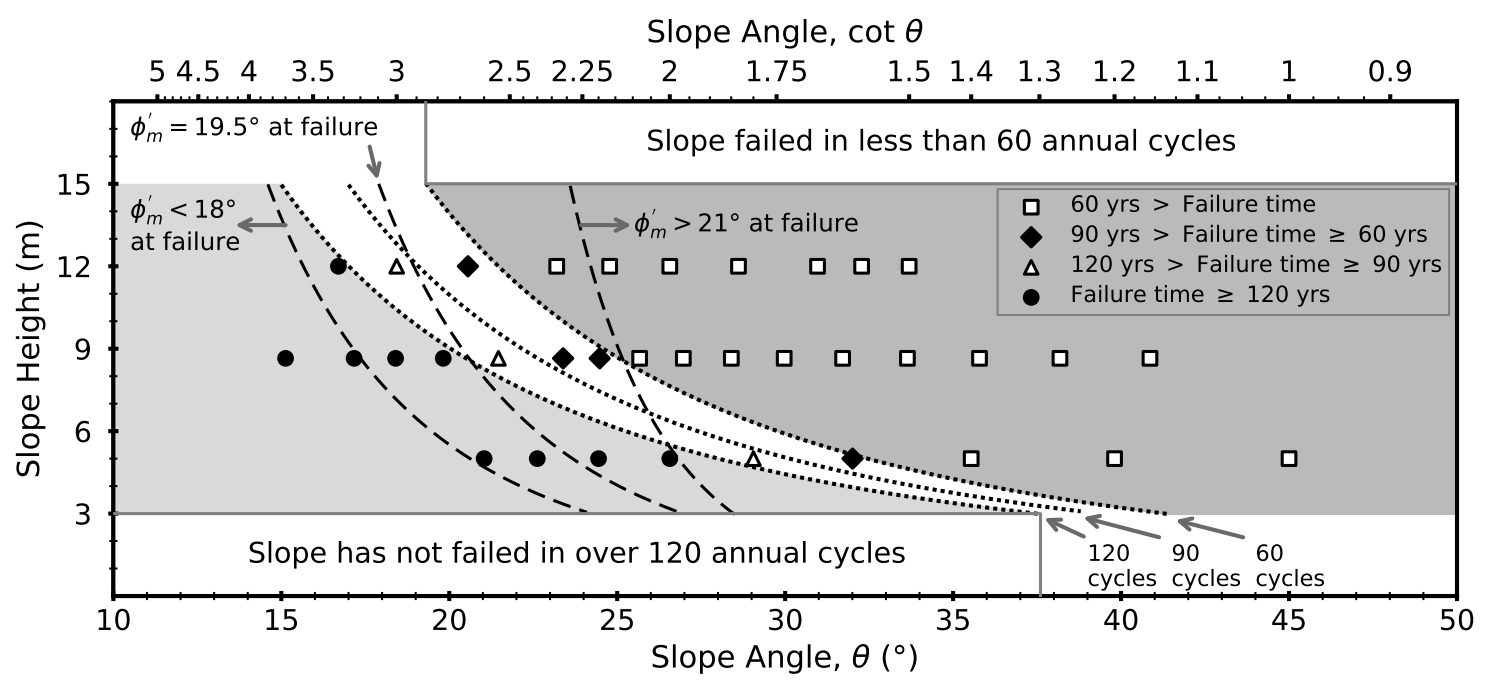

Figure 13: Slope geometry, number of annual cycles to failure and mobilised friction angle at failure for strain-softening curve (B). 


\section{Discussion}

The adopted modelling approach (Postill et al., 2020) has been validated against deformation and pore pressure measurements from centrifuge testing (Take and Bolton, 2011) and from field measurements of pore pressure (Postill et al., 2021). The strain-softening model replicates behaviour from peak, via fully softened strength (approximating critical state as per Skempton, 1970) through to residual strength.

Previous modelling of first-time failures in stiff clays tended to cap strength reduction at the average back analysed failure strength $\left(\phi^{\prime}=13^{\circ}, c^{\prime}=2 \mathrm{kPa}\right.$ : see for example Potts et al., 1997; Ellis and O'Brien, 2007; Summersgill et al., 2017b). However studies have shown that plastic shear strains can exceed the level required (20\%) to reach this arbitrary minimum (reaching as high as $\approx 50 \%$; Potts et al., 1997).

To address this, later work allowed additional strain-softening beyond the average field failure strength towards a residual value (characterised by $c^{\prime}=0$ and reduction in $\phi^{\prime}$ : Rouainia et al., 2020; Postill et al., 2021). This decision was informed by the discussion in Leroueil (2001) regarding the progressive failure mechanism with localised softening to residual, and other sections remaining closer to peak which produces an average mobilised strength close to the back-analysed value. This is supported by Cooper et al. (1998) discussing the Selbourne cutting trial where strength reduction approaching residual $\left(\phi^{\prime}=14^{\circ}, c^{\prime}=0 \mathrm{kPa}\right)$ near the slope toe was thought to have occurred.

Mesri and Shahien (2003) also highlight the likely occurrence of materials at residual strength on shear surfaces in first-time failures. This behaviour is seen in Figure 10 with softening to residual seen at or near the slope toe. The inclusion of a strain-softening model that describes full post peak behaviour via a fully softened strength to residual is thought to be justified in reproducing observed field behaviour.

\subsection{Effect of Slope Angle and Height}

The work summarised here demonstrates the relative effect that varying slope height and angle have on the rate of deterioration and time to failure of cut slopes in over-consolidated highplasticity clays. For example Figure 6, Figure $9 \mathrm{~b}$ and Figure $9 \mathrm{c}$ demonstrate the relationship between cut slope angle and design life, with even small decreases in slope angle leading to a large increase in time to failure (e.g. an increase from 38 years to 87 years with a $5.5^{\circ}$ decrease in slope angle from $30^{\circ}$ to $24.5^{\circ}$ ). This clearly illustrates the benefit of adopting a shallower slope angle at the design phase, however the specific values reported are controlled by the adopted material parameters.

Figure 11a demonstrates the large effect slope height has on time to failure, where for a common slope angle ( 1 in 2 ), a decrease in slope height from $12 \mathrm{~m}$ to $5 \mathrm{~m}$ leads to an increase in life 
from 25 to 150 years. This is primarily of interest when evaluating the potential deterioration of existing assets. It may also be a consideration when selecting route alignment in new designs.

Three broad categories of slope are identified in Figure 9 and Figure 11, the first defines the lower bounds of slope stability. Slope geometries in this category would only be plausible designs with some form of engineered measure to increase their design life and would likely be applicable to locations where available land take is severely restricted. This is potentially useful in preliminary design selection for new infrastructure.

The second category includes slopes where seasonal ratcheting will cause failure and the slope life is less than may be considered desirable. This category is useful both for evaluating the potential lifespan of existing slopes as well as to derive suitable design parameters for new slope infrastructure.

The third category defines the upper bounds of potential instability, above which failure is unlikely to occur during typical design life, which may aid asset owners in making a rapid characterisation of asset vulnerability in their existing inventory and from an asset management perspective, allowing them to prioritise (or exclude) slopes for more detailed assessment. From a new design and build perspective, this may also have economic benefits in allowing designers to remove overly conservative (and hence expensive) designs making their proposed solution more competitive.

\subsection{Effect of Strain-Softening}

Figure 9a shows that the adopted strain-softening relationship influences the time to failure for the same slope geometry, with materials that reduce in strength towards residual at lower strains remaining stable for less time. Given the importance of the strain-softening behaviour in controlling deterioration rate and time to failure, to undertake this modelling to produce design charts for other materials it is key that the complete stress-strain relationship, from peak to residual strength and the strains required to reach such conditions for a material, are understood.

The residual factor at failure derived from Figures 9 and 11 can be used to estimate the mobilised friction angle or $\phi_{m}^{\prime}$ can be estimated directly from Figure 12 which informs design parameter selection for use in limit equilibrium analysis and hence design for shallow firsttime failure in clay cut slopes due to seasonal ratcheting. Note that for $\phi_{m}^{\prime}>$ fully softened strength there is also a cohesive contribution to strength.

The analyses conducted clearly indicate that designs based on residual strength parameters will result in overly conservative solutions with design lives far greater than may be required. This study therefore reinforces that the use of residual strength parameters is not necessary or economically justifiable when considering first-time failures. 
The use of mobilised friction angle allows recommendations for design parameters for use in limit equilibrium analyses to be made without requiring stress conditions to be explicitly stated. However, the critical failure surface, which can be informed by the modelling (e.g., Figures 7 and 10), and worst-case pore water pressures associated with the failure surface, are required.

\subsection{Hydrology}

Within the modelling summarised, failure of slopes occurs in the winter when seasonal pore pressures reach worst case conditions, as per the behaviour observed on the UK rail network and replicated by Postill et al. (2020). It is suggested that slope design using limit equilibrium analysis to examine stability related to seasonal ratcheting should include a conservative nearsurface water table. In addition, recent work has demonstrated the importance of changing climate and long duration wet periods increasing deterioration rates (Rouainia et al., 2020; Postill et al., 2021) and so the effects of realistic weather patterns and how these may change over time should be considered.

Surface cracking in expansive soils can lead to increased infiltration and increase the occurrence of shallow failures in less steep slopes (Pei et al., 2020; Xie et al., 2020). Expansive soils under cyclic rainfall have also contributed to failures in very shallow angle natural slopes (Hou et al., 2013). This behaviour is not captured in this work (although the effect of increased near surface permeability is included in Postill et al., 2021) and may lead to an overestimation of time to failure for shallower slopes.

\subsection{Other Considerations}

The analyses presented are for an idealised problem, stress cycles are uniform and extreme events causing prolonged wetting, which increases deterioration (Postill et al., 2021), along with climate change (Rouainia et al., 2020) have been omitted; and a uniform material with simple stress history has been modelled.

Engineered slopes have very complex stress histories and spatial variability of material properties exists. In particular, the addition of structural discontinuities can control slope behaviour. In addition, the influence of vegetation rooting on shear strength has been omitted from this study (see for example Woodman et al., 2020).

The effect of cyclic vehicle loading which could accelerate deterioration in the strength and stiffness of infrastructure slopes is not captured in this work. For a thorough treatment of the modelling of this behaviour readers are directed to Wichtmann and Triantafyllidis (2018) and for a broad discussion of the effects of cyclic behaviour on slope stability see Leroueil (2001).

Furthermore, two-dimensional analyses tend to produce conservative factors of safety when compared to three-dimensional analyses (Cavounidis, 1987; Gao et al., 2013). 
This study presents a framework for evaluating seasonal ratcheting effects on slopes that informs selection of mobilised strength parameters for a given design life. While design approaches to minimise risk of failure during the operational life of an asset can be suggested, there must be an appreciation of several factors:

- The variable nature of weather patterns (Alexander and Jones, 2000; Jenkins et al., 2009; Murphy et al., 2019) and how they can effect time to failure (Alonso et al., 2003; Oh and Lu, 2015; Postill et al., 2020, 2021; Rouainia et al., 2020)

- Spatial and temporal heterogeneity of soil (Phoon and Kulhawy, 1999; Griffiths and Fenton, 2004; Dixon et al., 2019; Stirling et al., 2020)

- The influence of site-specific problems (e.g. localised drainage failure, the presence and orientation of pre-existing discontinuities or other stratigraphic features and land use changes)

- The influence of vegetation and vegetation management (Smethurst et al., 2015; Briggs et al., 2016; Tsiampousi et al., 2017)

Therefore, general guidance is not appropriate for all design instances. In particular, high-risk projects should consider detailed analysis of material behaviour and modelling of the effects of real weather patterns as discussed. 


\section{Conclusions}

An investigation has been undertaken into the effects of strain-softening behaviour and slope geometry on the mechanism of seasonal ratcheting and progressive failure of engineered clay cut slopes. The study was motivated by observations of shallow slope failures in cut slopes decades after construction related negative excess pore water pressures have fully dissipated (e.g. on the UK rail network). This paper details a numerical modelling approach to investigate time dependent slope deformations (down slope ratcheting) under cycles of seasonal wetting and drying.

The work has demonstrated that cut slopes constructed within high-plasticity clays with shrinkswell potential, at angles greater than the residual friction angle of the material, will experience seasonal ratcheting driven by weather driven pore pressure cycles. These stress cycles can lead to shallow first-time progressive failure. This study has shown that the time frame in which slope failure occurs due to seasonal ratcheting is dependent on the slope geometry and strainsoftening behaviour of the material. Recent work has also demonstrated that the time spent at near hydrostatic conditions, and the magnitude of the annual stress cycles affect the rate of deterioration (Postill et al., 2020).

The following trends in behaviour have been observed and conclusions drawn:

- Annual stress cycles cause strength deterioration, leading to shallow first-time failures in high-plasticity clay slopes

- Slopes constructed at angles less than the minimum friction angle of the soil will not fail due to seasonal ratcheting although additional care should be taken with expansive soils where desiccation cracking may occur which can lead to failures at shallow angles

- Long-term strength deterioration explains why slopes that appear stable fail during a wet period when they have experienced the same or greater magnitude and duration of wetting previously

- Behaviour of steep slopes is governed by peak strength and post peak strain-softening has little influence on behaviour

- Soils with more rapid post peak strength reduction profiles fail at higher mobilised strengths and failure surfaces are deeper

- Low height slopes are much more stable than higher slopes of the same angle

- The shallower the slope angle, the smaller and shallower the failure surface

- Use of fully softened strength parameters for the assessment of long-term stability will likely result in slopes that fail due to seasonal ratcheting at some time in the future, and depending on the slope geometry, this may occur within the design life of the asset

- Use of residual strength parameters for the assessment of long-term stability via first-time failure is inappropriate as slopes will not mobilise this strength by seasonal ratcheting within the design life of the asset

- For meaningful analysis of other clay slopes that experience seasonal ratcheting, the strain-softening behaviour of the material must be understood 


\section{Acknowledgements}

The authors gratefully acknowledge Loughborough University for funding the work presented, and the iSMART (EPSRC project EP/K027050/1) and ACHILLES project group (EPSRC programme grant EP/R034575/1) for their support in preparing this manuscript.

The data (Helm et al., 2021) used in the preparation of this publication is available from the following source: https://doi.org/10.25405/data.ncl.16598672. 


\section{References}

Al-Tabbaa A and Wood DM (1987) Some measurements of the permeability of kaolin. Géotechnique 37(4): 499-514, http://dx.doi.org/10.1680/geot.1987.37.4.499.

Alexander L V. and Jones PD (2000) Updated precipitation series for the U.K. and discussion of recent extremes. Atmospheric Science Letters 1(2): 142-150, http://dx.doi.org/10.1006/asle. 2000.0016.

Alonso EE, Gens A and Delahaye CH (2003) Influence of rainfall on the deformation and stability of a slope in overconsolidated clays: a case study. Hydrogeology Journal 11(1): 174-192, http://dx.doi.org/10.1007/s10040-002-0245-1.

Briggs KM, Smethurst JA, Powrie W, et al. (2016) The influence of tree root water uptake on the long term hydrology of a clay fill railway embankment. Transportation Geotechnics 9: 31-48, http://dx.doi.org/10.1016/j.trgeo.2016.06.001.

BSI (2004) BS EN 1997-1:2004+A1:2013. Eurocode 7. Geotechnical design. General rules. BSI, Milton Keynes, UK.

Castellanos BA, Brandon TL and VandenBerge DR (2016) Use of fully softened shear strength in slope stability analysis. Landslides 13(4): 697-709, http://dx.doi.org/10.1007/s10346-0150597-y.

Cavounidis S (1987) On the ratio of factors of safety in slope stability analyses. Géotechnique 37(2): 207-210, http://dx.doi.org/10.1680/geot.1987.37.2.207.

Cekerevac C and Laloui L (2004) Experimental study of thermal effects on the mechanical behaviour of a clay. International Journal for Numerical and Analytical Methods in Geomechanics 28(3): 209-228, http://dx.doi.org/10.1002/nag.332.

Chandler RJ and Skempton AW (1974) The design of permanent cutting slopes in stiff fissured clays. Géotechnique 24(4): 457-466, http://dx.doi.org/10.1680/geot.1974.24.4.457.

Cooper MR, Bromhead EN, Petley DJ and Grants DI (1998) The Selborne cutting stability experiment. Géotechnique 48(1): 83-101, http://dx.doi.org/10.1680/geot.1998.48.1.83.

Dixon N, Crosby CJ, Stirling R et al. (2019) In situ measurements of near-surface hydraulic conductivity in engineered clay slopes. Quarterly Journal of Engineering Geology and Hydrogeology 52(1): 123-135, http://dx.doi.org/10.1144/qjegh2017-059.

Dobbie KE (1992) Till Geotechnics and Ice Sheet Dynamics. PhD Thesis, University of Edinburgh. https://era.ed.ac.uk/handle/1842/13666.

Ellis EA and O'Brien AS (2007) Effect of height on delayed collapse of cuttings in stiff clay. Proceedings of the Institution of Civil Engineers - Geotechnical Engineering 160(2): 73-84, http://dx.doi.org/10.1680/geng.2007.160.2.73.

Farrokhpay S, Ndlovu B and Bradshaw D (2016) Behaviour of swelling clays versus nonswelling clays in flotation. Minerals Engineering 96-97: 59-66, http://dx.doi.org/10.1016/j. mineng.2016.04.011.

Galavi V and Schweiger HF (2010) Nonlocal Multilaminate Model for Strain Softening Analysis. International Journal of Geomechanics 10(1): 30-44, http://dx.doi.org/10.1061/(ASCE) 1532-3641(2010)10:1(30). 
Gao YF, Zhang F, Lei GH and Li DY (2013) An extended limit analysis of three-dimensional slope stability. Géotechnique 63(6): 518-524, http://dx.doi.org/10.1680/geot.12.T.004.

van Genuchten MT (1980) A Closed-form Equation for Predicting the Hydraulic Conductivity of Unsaturated Soils. Soil Science Society of America Journal 44(5): 892, http://dx.doi.org/10. 2136/sssaj1980.03615995004400050002x.

Griffiths DV and Fenton GA (2004) Probabilistic Slope Stability Analysis by Finite Elements. Journal of Geotechnical and Geoenvironmental Engineering 130(5): 507-518, http://dx.doi. org/10.1061/(ASCE)1090-0241(2004)130:5(507).

Helm PR, Postill H, Dixon N et al. (2021) Dataset: Strength parameter selection framework for evaluating the design life of clay cut slopes. Newcastle University. https://doi.org/10.25405/ data.ncl.16598672.

Highways England (2020) Design Manual for Roads and Bridges: The design of highway structures. Highways England, UK, CD 350 Revision 0.

Hou T, Xu G, Shen Y et al. (2013) Formation mechanism and stability analysis of the Houba expansive soil landslide. Engineering Geology 161: 34-43, http://dx.doi.org/10.1016/j.enggeo. 2013.04.010.

HS2 Ltd (2017) Transforming lives, building for the future: HS2 Sustainability Approach. High Speed Two (HS2) Limited, Birmingham, UK.

Itasca (2011) FLAC - Fast Lagrangian Analysis of Continua. Version 7. Itasca Consulting Group Inc, Minneapolis, USA.

Jenkins G, Perry M, Prior J and Woodworth P (2009) UKCIP08: the climate of the United Kingdom and recent trends. Met Office Hadley Centre, Exeter, UK.

Kovacevic N, Hight DW and Potts DM (2007) Predicting the stand-up time of temporary London Clay slopes at Terminal 5, Heathrow Airport. Géotechnique 57(1): 63-74, http://dx.doi. org/10.1680/geot.2007.57.1.63.

Leroueil S (2001) Natural slopes and cuts: movement and failure mechanisms. Géotechnique 51(3): 197-243, http://dx.doi.org/10.1680/geot.2001.51.3.197.

Lupini JF, Skinner AE and Vaughan PR (1981) The drained residual strength of cohesive soils. Géotechnique 31(2): 181-213, http://dx.doi.org/10.1680/geot.1981.31.2.181.

Mayne PW and Kulhawy FH (1982) K0 - OCR relationships in soil. Journal of the Geotechnical Engineering Division 108(GT6): 851-872, http://dx.doi.org/10.1061/ajgeb6.0001306.

Mesri G and Cepeda-Diaz AF (1986) Residual shear strength of clays and shales. Géotechnique 36(2): 269-274, http://dx.doi.org/10.1680/geot.1986.36.2.269.

Mesri G and Shahien M (2003) Residual Shear Strength Mobilized in First-Time Slope Failures. Journal of Geotechnical and Geoenvironmental Engineering 129(1): 12-31, http://dx.doi. org/10.1061/(asce)1090-0241(2003)129:1(12).

Murphy JM, Harris GR, Sexton DMH et al. (2019) UKCP18 Land Projections: Science Report. Met Office Hadley Centre, Exeter, UK. Available at: https://www.metoffice.gov.uk/pub/ data/weather/uk/ukcp18/science-reports/UKCP18-Land-report.pdf. 
Network Rail (2018) Earthworks Technical Strategy. Network Rail, Milton Keynes, UK. Available at: https://www.networkrail.co.uk/wp-content/uploads/2018/07/Earthworks-Technical-Strategy. pdf.

Oh S and Lu N (2015) Slope stability analysis under unsaturated conditions: Case studies of rainfall-induced failure of cut slopes. Engineering Geology 184: 96-103, http://dx.doi.org/10. 1016/j.enggeo.2014.11.007.

Pei P, Zhao Y, Ni P and Mei, G (2020) A protective measure for expansive soil slopes based on moisture content control. Engineering Geology 269: 105527, http://dx.doi.org/10.1016/j. enggeo.2020.105527.

Petley DN, Higuchi T, Petley DJ, Bulmer MH and Carey J (2005) Development of progressive landslide failure in cohesive materials. Geology 33(3): 201, http://dx.doi.org/10.1130/G21147. 1 .

Phoon K-K and Kulhawy FH (1999) Characterization of geotechnical variability. Canadian Geotechnical Journal 36(4): 612-624, http://dx.doi.org/10.1139/t99-038.

Postill H, Dixon N, Fowmes G, El-Hamalawi A and Take WA (2020) Modelling seasonal ratcheting and progressive failure in clay slopes: a validation. Canadian Geotechnical Journal 57(9): 1265-1279, http://dx.doi.org/10.1139/cgj-2018-0837.

Postill H, Helm PR, Dixon N et al. (2021) Forecasting the long-term deterioration of a cut slope in high-plasticity clay using a numerical model. Engineering Geology 280: 105912, http://dx.doi.org/10.1016/j.enggeo.2020.105912.

Potts DM, Kovacevic N and Vaughan PR (1997) Delayed collapse of cut slopes in stiff clay. Géotechnique 47(5): 953-982, http://dx.doi.org/10.1680/geot.1997.47.5.953.

Rouainia M, Helm P, Davies O and Glendinning S. (2020) Deterioration of an infrastructure cutting subjected to climate change. Acta Geotechnica 15(10): 2997-3016, http://dx.doi.org/ 10.1007/s11440-020-00965-1.

Saito M (1980) Semi-logarithmic representation for forecasting slope failure. In Proceedings of the International Symposium on Landslides. New Delhi, India, vol. 1, pp. 321-324.

Schofield A and Wroth P (1968) Critical State Soil Mechanics. McGraw-Hill, US.

Sivakumar V, Glynn D, Cairns P and Black JA (2009) A new method of measuring plastic limit of fine materials. Géotechnique 59(10): 813-823, http://dx.doi.org/10.1680/geot.2009.59.10. 813.

Skempton AW (1964) Long-Term Stability of Clay Slopes. Géotechnique 14(2): 77-102, http://dx.doi.org/10.1680/geot.1964.14.2.77.

Skempton AW (1970) First-Time Slides in Over-Consolidated Clays. Géotechnique 20(3): 320-324, http://dx.doi.org/10.1680/geot.1970.20.3.320.

Skempton AW (1984) Slope Stability of Cuttings in Brown London Clay. In Selected Papers on Soil Mechanics. Thomas Telford, London, UK, pp. 241-250. http://dx.doi.org/10.1680/sposm. 02050.0021 .

Skempton AW (1995) Embankments and cuttings on the early railways. Construction History 11: 33-49, Available at: https://www.jstor.org/stable/41615443. 
Smethurst JA, Briggs KM, Powrie W, Ridley A and Butcher DJE (2015) Mechanical and hydrological impacts of tree removal on a clay fill railway embankment. Géotechnique $\mathbf{6 5}(\mathbf{1 1})$ : 869-882, http://dx.doi.org/10.1680/jgeot.14.P.010.

Sridharan A, Rao GV and Pandian RS (1973) Volume Change Behaviour of Partly Saturated Clays During Soaking and the Role of Effective Stress Concept. Soils and Foundations 13(3): 1-15, http://dx.doi.org/10.3208/sandf1972.13.3_1.

Stark TD, Choi H and McCone S (2005) Drained Shear Strength Parameters for Analysis of Landslides. Journal of Geotechnical and Geoenvironmental Engineering 131(5): 575-588, http://dx.doi.org/10.1061/(ASCE)1090-0241(2005)131:5(575).

Stirling RA, Toll DG, Glendinning S et al. (2020) Weather-driven deterioration processes affecting the performance of embankment slopes. Géotechnique. Published online ahead of print, http://dx.doi.org/10.1680/jgeot.19.SiP.038.

Summersgill FC, Kontoe S and Potts DM (2017a) On the use of nonlocal regularisation in slope stability problems. Computers and Geotechnics 82: 187-200, http://dx.doi.org/10.1016/ j.compgeo.2016.10.016.

Summersgill FC, Kontoe S and Potts DM (2017b) Stabilisation of excavated slopes in strainsoftening materials with piles. Géotechnique 68(7): 1-14, http://dx.doi.org/10.1680/jgeot.17.P. 096.

Take WA (2003) The influence of seasonal moisture cycles on clay slopes. PhD Thesis, University of Cambridge. http://dx.doi.org/https://doi.org/10.17863/CAM.19045.

Take WA and Bolton MD (2011) Seasonal ratcheting and softening in clay slopes, leading to first-time failure. Géotechnique 61(9): 757-769, http://dx.doi.org/10.1680/geot.9.P.125.

Tsiampousi A, Zdravkovic L and Potts DM (2017) Numerical study of the effect of soilatmosphere interaction on the stability and serviceability of cut slopes in London Clay. Canadian Geotechnical Journal 54(3): 405-418, http://dx.doi.org/10.1139/cgj-2016-0319.

Wang Y and Siu W (2006) Structure characteristics and mechanical properties of kaolinite soils. I. Surface charges and structural characterizations. Canadian Geotechnical Journal 43(6): 587600, http://dx.doi.org/10.1139/T06-026.

Wichtmann T and Triantafyllidis T (2018) Monotonic and cyclic tests on kaolin: a database for the development, calibration and verification of constitutive models for cohesive soils with focus to cyclic loading. Acta Geotechnica 13(5): 1103-1128, http://dx.doi.org/10.1007/s11440017-0588-3.

Woodman ND, Smethurst JA, Roose T et al. (2020) Mathematical and computational modelling of vegetated soil incorporating hydraulically-driven finite strain deformation. Computers and Geotechnics 127: 103754, http://dx.doi.org/10.1016/j.compgeo.2020.103754.

Xie C, Ni P, Xu M, Mei G and Zhao Y (2020) Combined measure of geometry optimization and vegetation for expansive soil slopes. Computers and Geotechnics 123: 103588, http://dx.doi.org/10.1016/j.compgeo.2020.103588. 


\section{A1 Appendix: Numerical Modelling Framework}

Saturated and unsaturated behaviour has been modelled as a water and air phase within a porous soil medium, with Bishop's generalised effective stress $\left(\sigma_{B}^{\prime}\right)$ used to combine these three phases into a single stress state variable, see Eqn. A1.

$$
\sigma_{B}^{\prime}=\left(\sigma-u_{a}\right)+S_{w}\left(u_{a}-u_{w}\right)
$$

Where $\sigma=$ total stress; $u_{a}=$ pore air pressure; $u_{w}=$ pore water pressure; $\left(\sigma-u_{a}\right)=$ net stress; $s=\left(u_{a}-u_{w}\right)=$ matric suction; $S_{w}=$ degree of saturation.

A van Genuchten (1980) soil water retention curve (see Eqn. A2) related soil water content and matric suction.

$$
s=\alpha\left[S_{e}^{-(1 / m)}-1\right]^{1-m}
$$

Where $s=$ matric suction; $S_{e}=\left(S_{w}-S_{w}^{r}\right) /\left(1-S_{w}^{r}\right)=$ effective saturation; $S_{w}^{r}=$ residual saturation; $\alpha=$ van Genuchten fitting parameter $(\mathrm{kPa})$; and $m=$ van Genuchten fitting parameter.

The relative hydraulic conductivity can be obtained using van Genuchten's (1980) equations (see Eqn. A3 and Eqn. A4).

$$
\begin{aligned}
K_{r}^{w} & =K_{\text {sat }} \cdot S_{e}^{0.5}\left[1-\left(1-S_{e}{ }^{1 / m}\right)^{m}\right]^{2} \\
K_{r}^{a} & =K_{\text {sat }} \cdot\left(1-S_{e}\right)^{0.5}\left[1-S_{e}{ }^{1 / m}\right]^{2 m}
\end{aligned}
$$

Where $K_{r}^{w}=$ unsaturated hydraulic conductivity of water phase $(\mathrm{m} / \mathrm{s}) ; K_{r}^{a}=$ unsaturated hydraulic conductivity of air phase $(\mathrm{m} / \mathrm{s})$; and $K_{\text {sat }}=$ saturated hydraulic conductivity $(\mathrm{m} / \mathrm{s})$.

\section{Nonlocal Strain-Softening Formulation}

To reduce mesh dependency in the softening model, a nonlocal regulatory approach was adopted. Local plastic strains (Eqn. A5) are averaged to derive nonlocal plastic strains (Galavi and Schweiger, 2010; Summersgill et al., 2017a).

$$
\Delta \varepsilon^{p s}=\sqrt{\left[\frac{1}{2}\left(\Delta \varepsilon_{1}^{p s}-\Delta \varepsilon_{m}^{p s}\right)^{2}+\frac{1}{2}\left(\Delta \varepsilon_{m}^{p s}\right)^{2}+\frac{1}{2}\left(\Delta \varepsilon_{3}^{p s}-\Delta \varepsilon_{m}^{p s}\right)^{2}\right]}
$$

Where $\Delta \varepsilon^{p s}=$ local plastic shear strains; $\Delta \varepsilon_{1}^{p s}$ and $\Delta \varepsilon_{3}^{p s}=$ principal local plastic shear strain increments and $\Delta \varepsilon_{m}^{p s}=\frac{1}{3}\left(\Delta \varepsilon_{1}^{p s}+\Delta \varepsilon_{3}^{p s}\right)$.

The nonlocal plastic strain $\left(\varepsilon_{p}^{*}\right)$ at point $\left(x_{n}\right)$ is calculated using Eqn. A6.

$$
\varepsilon_{p}^{*}=\frac{1}{V_{w}} \iiint \omega^{\prime}\left(x_{n}^{\prime}\right) \varepsilon^{p s}\left(x_{n}+x_{n}^{\prime}\right) d x_{1}^{\prime} d x_{2}^{\prime} d x_{3}^{\prime}
$$

Where $V_{w} \iiint \omega^{\prime} d x_{1}^{\prime} d x_{2}^{\prime} d x_{3}^{\prime}=$ weighted volume; $\omega^{\prime}\left(x_{n}^{\prime}\right)$ is the weighting function; $\varepsilon^{p s}\left(x_{n}+x_{n}^{\prime}\right)=$ local plastic strain at different calculation points; $x_{n}=$ global (target) coordinate; $x_{n}^{\prime}=$ local (reference) coordinate. 
The weighting function (Galavi and Schweiger, 2010) is shown in Eqn. A7.

$$
\omega^{\prime}(r)=\frac{r}{l} e^{\left(\frac{r}{l}\right)^{2}}
$$

Where $l=$ internal length (m) and $r=$ distance to adjacent calculation points (m).

\section{Material Relationships}

Bulk and shear moduli are a function of the specific volume $(\nu)$ and mean effective stress $\left(\sigma^{\prime}\right)$ as per Schofield and Wroth (1968), see Eqn. A8 and Eqn. A9.

$$
\begin{gathered}
K=\frac{\nu \cdot \sigma^{\prime}}{\kappa} ; \min 2000 \mathrm{kPa} \\
G=\frac{3(1-2 \mu)}{2(1+\mu)} \cdot K
\end{gathered}
$$

Where $K=$ bulk modulus $(\mathrm{kPa}) ; G=$ shear modulus $(\mathrm{kPa}) ; \kappa=$ gradient of the swelling line; $\mu=$ Poisson's ratio.

$\nu$ of the soil is calculated as per Schofield and Wroth (1968) in the $\nu: \ln \left(\sigma^{\prime}\right)$ space (Eqn. A10 and Eqn. A11).

$$
\begin{gathered}
\nu=\nu_{\lambda}-\lambda \cdot \ln \frac{\sigma^{\prime}}{\sigma_{r e f}} ; \text { normal consolidation line } \\
\nu=\nu_{\kappa}-\kappa \cdot \ln \frac{\sigma^{\prime}}{\sigma_{r e f}} ; \text { swelling lines }
\end{gathered}
$$

Where $\lambda=$ gradient of the normal consolidation line; $\sigma_{r e f}=$ reference pressure $(\mathrm{kPa}) ; \nu_{\lambda}=$ original specific volume at reference pressure; $\nu_{\kappa}=$ specific volume at reference pressure following the swelling line. 